\title{
Validation of the Resilience Competencies Scale (RCS) for Applications among American Indian Youth
}

\author{
Melanie Hockenberry \\ West Virginia University
}

Follow this and additional works at: https://researchrepository.wvu.edu/etd

\section{Recommended Citation}

Hockenberry, Melanie, "Validation of the Resilience Competencies Scale (RCS) for Applications among American Indian Youth" (2011). Graduate Theses, Dissertations, and Problem Reports. 764.

https://researchrepository.wvu.edu/etd/764

This Thesis is protected by copyright and/or related rights. It has been brought to you by the The Research Repository @ WVU with permission from the rights-holder(s). You are free to use this Thesis in any way that is permitted by the copyright and related rights legislation that applies to your use. For other uses you must obtain permission from the rights-holder(s) directly, unless additional rights are indicated by a Creative Commons license in the record and/ or on the work itself. This Thesis has been accepted for inclusion in WVU Graduate Theses, Dissertations, and Problem Reports collection by an authorized administrator of The Research Repository @ WVU. For more information, please contact researchrepository@mail.wvu.edu. 


\title{
Validation of the Resilience Competencies Scale (RCS) for Applications among American Indian Youth
}

\author{
Melanie Hockenberry
}

Thesis submitted to the College of Human Resources and Education at West Virginia

University in partial fulfillment of the requirements for the degree of

\author{
Master of Arts \\ In \\ Educational Psychology \\ Carol Markstrom, Ph.D., Chair \\ Kristin Moilanen, Ph.D., Committee member \\ Jessica Troilo Ph.D., Committee member \\ Department of Technology, Learning, and Culture \\ Morgantown, West Virginia \\ 2011
}

Keywords: American Indian; Adolescence; Resilience; Measurement

Copyright 2011 Melanie Hockenberry 


\begin{abstract}
Validation of the Resilience Competencies Scale (RCS) for Applications among

American Indian Youth

Melanie Hockenberry
\end{abstract}

Historical trauma, poverty, educational inequalities, and discrimination are among the many factors contributing to current problems, such as substance abuse, experienced by some American Indian youth today. Much of the literature on American Indian adolescents has been problem-focused; but it is also important to identify factors that are associated with resilient outcomes, such as personal, social, and ecological factors highlighted in models of resilience. As a step toward conducting such studies, it is necessary to have measures that are valid, reliable, and culturally-applicable for American Indian adolescents. Therefore, a mixed methods study (focus groups; survey) was conducted to examine the Resilience Competencies Scale (RCS) for its applicability among American Indian youth in Arizona by: (1) assessing the RCS for face and content validity through focus group discussions with American Indian youth; and (2) administering the RCS to a sample of American Indian youth along with other measures to examine concurrent and discriminant forms of validity along with reliability. The study was conducted in two phases with distinct samples from a reservation community in Arizona. Two volunteers from the tribe's youth council (one 19 year old female and one 18 year old male) met with the investigator on multiple occasions over two weeks to critically examine the RCS for face and content validity as well as cultural applicability. The RCS was revised based on focus group input. Phase 2 data collection occurred at the reservation high school and alternative school. Fifty-eight $9^{\text {th }}-12^{\text {th }}$ grade male and female American Indian students ranging from ages 15to 19 participated in the study. Students completed the RCS, the Psychosocial Inventory of Ego Strengths (PIES) and The Center for Epidemiological Studies-Depression (CES-D 10). Acceptable Cronbach's alphas were shown for all 20 items on the RCS and concurrent and discriminant validity were shown through significant correlations between the RCS, and with Hope and Purpose subscales and the CES-D 10. The validation of a measure of resilience for American Indian youth can serve as a useful research and clinical tool. 


\section{ACKNOWLEDGMENTS}

First and foremost I would like to express my gratitude to my committee chair, Dr. Carol Markstrom, for inviting me to the NCAI conference two years ago and taking me to my first ceremony on the reservation where this research was completed. I will always be thankful to her for really opening so many doors for me both academically and personally. I would also like to thank my committee member, Dr. Kristin Moilanen, for her extreme patience over the past few years and her guidance through the thesis process. . I would like to express my appreciation as well to my other committee member, Dr. Jessica Troilo, for her expertise in qualitative research and for really pushing me further to expand and develop my work that contributed greatly to the current study.

I would like to thank our West Virginia University Native American Studies program for the financial assistance and special thanks to the Native American Studies Coordinator, Ms. Bonnie Brown, for all of the guidance and emotional support she has provided throughout my undergraduate and graduate work. Thank you to Dr. Robert Henley for developing the RCS and for providing me the idea of this research. I would like to give a special thank you to all the participants and community members where the research was conducted.

I would like to thank my parents for all of their support over the years and always allowing me to create my own path. Thanks to my brother for always setting the bar high. A special thanks to my Aunt Karen for the countless emails, cards, and phone calls always encouraging me and being my biggest cheerleader especially during the final stretch of this process.

Lastly, I would like to thank my amazing daughter, Sierra, who makes every day of my life a blessing and gives reason to everything. Even at five years old, she picks me up when I 
need it most and I'm hopeful that one day she will understand the full magnitude of her contribution in this project. 


\section{Table of Contents}

Page

Abstract.....................................................................

Acknowledgments....................................................

Table of Contents................................................. v

List of Appendices................................................ vii

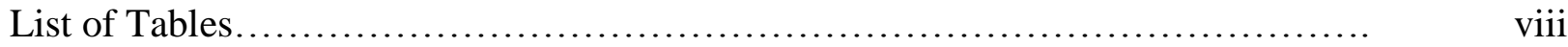

Chapter One: Introduction.......................................... 1

Resilience Competencies Scale (RCS) ............................. 2

Statement of the Problem...........................................

Statement of the Purpose......................................... 3

Contributions of this Research........................................ 4

Chapter Two: Literature Review

Foundational work in the Study of Resilience......................... 5

Resilience Defined............................................ 6

Models of Resilience...........................................

Sub-Factors in the RCS .......................................... 8

Developmental Psychopathology.................................. 10

American Indian At-Risk Nature...................................... 12

American Indian Resilience Defined............................... 14

Research on Resilience in American Indian Youth........................ 15

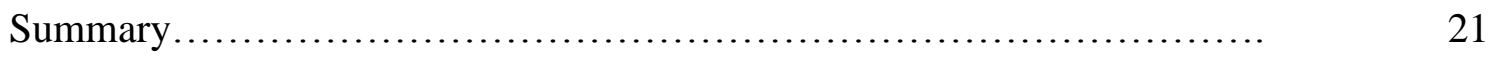


Chapter Three: Methods

Participants.................................................. 23

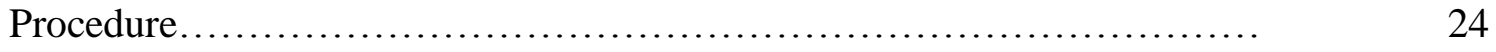

Instrumentation............................................... 29

Data Analysis.................................................. 31

Chapter Four: Results

Qualitative Results............................................ 33

Measurement Revision......................................... 36

Quantitative Results: Reliability $\ldots \ldots \ldots \ldots \ldots \ldots \ldots \ldots \ldots \ldots \ldots \ldots \ldots \ldots \ldots . \ldots \ldots \ldots$

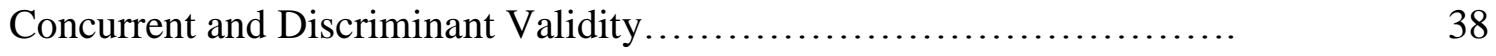

Chapter Five: Discussion

Qualitative Analysis........................................... 40

Quantitative Reliability and Validity............................. 43

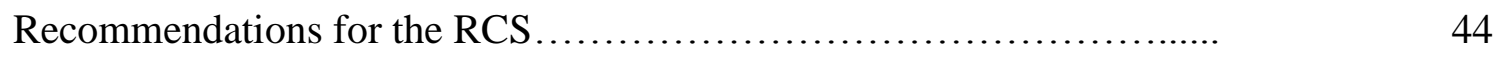

Limitations and Future Contributions............................ 44

References.................................................... 46 


\section{List of Appendices}

Appendices $\quad$ Page

Appendix A: Focus Group Assent Form: Phase $1 \ldots \ldots \ldots \ldots \ldots \ldots \ldots \ldots \ldots \ldots \ldots \ldots \ldots \ldots \ldots \ldots$

Appendix B: Youth Council Demographic Information: Phase $1 \ldots \ldots \ldots \ldots \ldots \ldots \ldots \ldots \ldots$

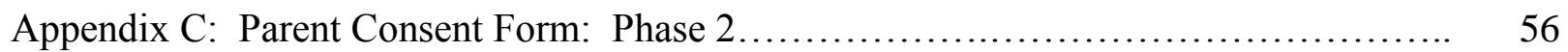

Appendix D: Youth Assent Form: Phase $2 \ldots \ldots \ldots \ldots \ldots \ldots \ldots \ldots \ldots \ldots \ldots \ldots \ldots \ldots \ldots \ldots$

Appendix E: Over 18 Assent Form: Phase 2 .................................. 63

Appendix F: Psychosocial Inventory of Ego Strengths (PIES) Subscales.............. 67

Appendix G: Original Resilience Competencies Scale (RCS) ..................... 69

Appendix H: Revised Resilience Competencies Scale (RCS) .................... 72

Appendix I: Center for Epidemiological Depression Scale (CES-D 10). .............. 74 


\section{List of Tables}

Table Page

1. Demographic information for high school students in phase $2(n=58) \ldots \ldots \ldots \ldots \ldots . \quad 75$

2. Focus Group Timeline.................................................. 76

3. Original Items from Resilience Competency Scale (RCS) and Revised Items after

Focus Groups with American Indian Youth................................... 78

4. Cronbach's Alphas for RCS, PIES Subscales, and CES-D 10 .................... 80

5. Reliability Statistics for PIES Subscale Hope.................................. 81

6. Reliability Statistics for PIES Subscale Purpose $\ldots \ldots \ldots \ldots \ldots \ldots \ldots \ldots \ldots \ldots \ldots \ldots \ldots 2$

7. Reliability Statistics for both PIES Subscales Hope and Purpose $\ldots \ldots \ldots \ldots \ldots \ldots \ldots . \quad 83$

8. Correlations Between RCS and PIES subscales (Hope and Purpose), and CES-D

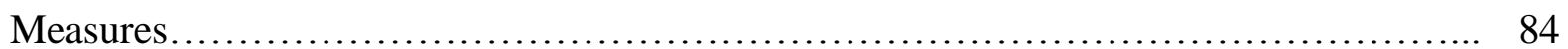

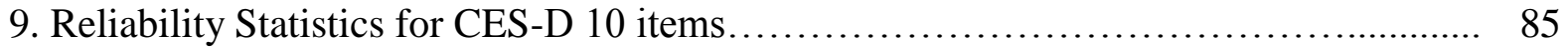

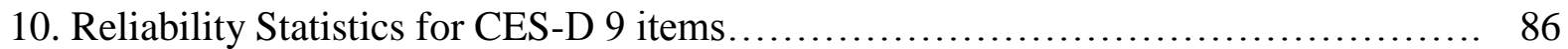

11. Reliability Statistics for RCS 20 items.................................... 87 
RCS VALIDATION 1

\section{Chapter 1}

\section{INTRODUCTION}

\section{Overview}

The American Indian population has been studied for decades with most researchers taking a problem or deficit-oriented approach (i.e., Whitbeck, 2011). While it is important and necessary for prevention and intervention efforts to understand the nature of and incidence levels of problems, it is also necessary to understand the factors that can protect against problematic outcomes for youth. Little research has been done on the positive attributes and protective factors within American Indians as individuals, families, communities, and the culture as a whole. It is known, however, with the traumatic history of oppression, the American Indian population has endured centuries of hardship and consequently great health disparities exist. American Indian/Alaska Natives (AI/AN) make up the smallest group of ethnic minorities at $1.5 \%$ of the population, while ranking the highest in health disparities among all ethnic minority

groups (Whitbeck, 2011). It is important to consider why these inequities still exist today among ethnic minority groups in comparison to the dominant society. Historical trauma, poverty, educational inequalities, and discrimination are among many factors contributing to the issues faced by American Indians today. A population that was once this country's sole inhabitants, American Indians have experienced a multitude of negative stereotypes which have led to their positive attributes being undervalued. This study seeks to highlight strengths among American Indians through a mixed methods research design to validate the Resilience Competencies Scale (RCS). 
RCS VALIDATION 2

\section{Resilience Competencies Scale (RCS)}

The RCS was developed to address the need for a resilience evaluation tool that potentially could be used across cultures, but has yet to be validated within any population (Henley, 2010). The RCS is a comprehensive youth self-report tool that consists of 20 items. The RCS measure was developed to capture the process of resilience which involves "how an actor influences his/her environment, in order to cope with or adapt to severely adverse events or threats and experience good outcomes" (Henley, 2010, p. 297). The RCS is one of the first measures developed to assess resilience including a full range of resilience competencies in youth. This range of resilience competencies allows for the participant to rate his/her attitudes and values and the ability to access social and other forms of support resources. The combinations of both individual attitudes and actions are responsible for an individual's total resilience competency (Henley, 2010).

The RCS provides a measurement device evaluating resilience as a process rather than an outcome. The RCS seeks to assess the range of factors from individual characteristics and responses, the family or the presence of a caring adult and peer relationships, to the individual's whole environment and community. This study highlights strengths among American Indian youth through the validation of a measure of resilience (i.e., the RCS) that has implications for use in future studies on strengths or protective factors among adolescents from this population.

\section{Statement of the Problem}

Studies have shown that in spite of the traumatic history, resilience is prevalent within American Indian cultures. Factors such as spirituality, traditional beliefs and practices, and related factors carried down from generation to generation are all shown to foster resilience (e.g., Brokenleg, 2010; Feinstein, Driving-Hawk \& Baartman, 2009; HeavyRunner \& Marshall, 2003; 
Montgomery, Miville, Winterowd, Jeffries \& Baysden, 2000). From this research, it seems clear that some protective factors associated with American Indians may not be the same protective factors associated with the dominant society. This reasoning justifies that studies need to look within American Indian cultures to acquire insights and guidance from individuals within their cultures. The at-risk nature of American Indians is well documented throughout the research, but more is needed to tease apart what is contributing to those youth who do not succumb to risk and are resilient and how these factors can help in the development and implementation of youth programs. To understand methodological issues, there is a measurement barrier that exists because of the lack of valid and reliable culturally applicable measures of resilience. A culturally appropriate measure for this population would fill a significant gap and allow for validation and evaluation of the true effectiveness of youth programs assisting vulnerable youth (Henley, 2010). Furthermore, the development of this RCS measure accounted for the combination of resilience attitudes (attitudes and values), and resilience actions (abilities to access support and offer support) to give a complete overall account for person's total resilience competency.

\section{Statement of the Purpose}

This research specifically allowed for input and guidance from American Indian youth in multiple focus groups to test for face and content validity of the RCS. Specifically, the purpose of this research study was to qualitatively and quantitatively assess the Resilience Competencies Scale (RCS) among American Indian youth by: (1) assessing the RCS measure for face and content validity with members from the tribe's youth council; and (2) administering the RCS along with the Psychosocial Inventory of Ego Strengths (PIES) and the Center for Epidemiological Studies Depression 10 Scale (CES-D 10) to American Indian high school students on the reservation to establish validity and reliability of the RCS. 


\section{Contributions of this Research}

A valid RCS could be a useful tool for the particular tribe in this study to assess effectiveness of youth programs on the reservation. From this research, other benefits may emerge such as a better understanding of what is needed to assist in the support of youth. Potentially, this research may contribute to the future development of youth programs to foster resilience in the tribe's youth. Finally, a culturally applicable RCS measure among American Indian youth in this specific cultural area of the country could potentially be generalized to American Indian youth from other tribes. Consequently, this study could benefit the area of research among American Indians and further contribute to the well-being of the American Indian population. 
RCS VALIDATION 5

\section{CHAPTER 2}

\section{LITERATURE REVIEW}

\section{Overview}

The purpose of this chapter is to review previous literature relevant to this research study. First, the chapter begins with the history of resilience and how it has evolved over the past decades. Also, this chapter shows the diversity that exists in defining the term "resilience," from scholarly definitions to the perspectives expressed by American Indians. Resilience theory and associated models of resilience, developmental psychopathology and the risk and protective factor framework all serve as the theoretical and empirical base for this present research. The atrisk nature of American Indians will be addressed by discussing historical trauma and statistics indicative of problems and health disparities among this population. Finally, a review of the related literature on resilience among American Indian youth is examined to support this research and the validation of the RCS.

\section{Resilience Theory}

Foundational work in the study of resilience. Research in the field of resilience evolved in the 1970s from Norman Garmezy’s early work with patients with schizophrenia. Garmezy and his students began to look at competent children of mentally ill parents in a research program named Program Competence (Garmezy, 1973). Program Competence began at the University of Minnesota and yielded years of research resulting in a better understanding of children at risk for psychopathology, the effects of stressful events on competent children, and protective/competence factors influencing stress resistance in children (Garmezy, Masten, \& Tellegen, 1984). Garmezy's measurement of competence in the 1970s study was directed at understanding the linkages between competence, adversity, internal functioning, individual and 
family attributes (Luthar, 2003). Multiple studies were conducted from a normal school cohort to children in homeless shelters and war refugees, with a primary focus on competence, risk, and resilience across studies. As a result of studies on Garmezy's Program Competence over the course of years, a general framework for conceptualizing and operationalizing the study of resilience evolved (Luthar, 2003).

Researchers in the field of resilience first began looking at resilience as an individual trait, but later realized that the concept of resilience was multidimensional, involving psychological (e.g., internal problem solving skills, coping and adaptations strategies) and social factors (e.g., caring adults, peers, and community) (Henley, 2010). Arrington and Wilson (2000) also suggested that resilience is a process consisting of both the environmental and the individual characteristics that can be fostered by protective processes. The concept of resilience as a process involves using assets or resources to overcome risks demonstrating resilience (Fergus \& Zimmerman, 2005).

Resilience defined. Definitions of resilience have been an ongoing issue of debate in the field because there is no universal definition. Garmezy (1991) defined resilience as the capacity to recover and maintain adaptive behavior after insult. Masten suggested that "resilience refers to a class of phenomena characterized by good outcomes in spite of serious threats to adaptation or development" (Masten, 2001, p. 228). Luthar, Cicchetti, and Becker (2000) defined resilience as "a dynamic process encompassing positive adaptation within the context of significant adversity and implicit within this notion are two critical conditions: (1) exposure to significant threat or severe adversity; and (2) the achievement of positive adaptation despite major assaults on the developmental process" (p. 543). Many scholars argue that multiple variations exist in definitions, operationalization, and measurement of key constructs (Luthar et al., 2000). Hence, 
the definition of resilience is also evolving from this concept of defining resilience as an outcome to looking at resilience as a process. Therefore, it is important in measurement development to capture resilience as a process and not simply an outcome.

Models of resilience. Protective factors are related to resilience because they are the aspects of the individual or the environment that are associated with the resilient outcomes. Garmezy (1983) defined protective factors as "those attributes of persons, environments, situations, and events that appear to temper predictions of psychopathology based on an individual's at-risk status" (p. 73). Acknowledging and building upon protective factors within the American Indian population will be an integral part in developing and implementing resilience based youth programs with the expectation that this research will play a part by documenting the validity and reliability of a measure that can be used to examine the success of such programs.

Resilience theory helps give support to this study of why some youth can grow up successfully while being faced with adversity and others cannot. Garmezy et al. (1984) introduced three basic models of resilience in a multivariate regression framework: the compensatory model, the protective model, and the challenge model. The compensatory model examines how compensatory variables may reduce poor outcomes associated with risk factors. The compensatory variable does not interact with the risk factor, but has a direct influence on the outcome. For example, while examining academic competence as the outcome and parental conflict as the risk factor, a compensatory factor could be a teacher. The challenge model explains how a risk factor can be a positive if it is not too excessive yet not too little. A moderate amount of stress can help the individual achieve or strengthen competence by overcoming a particular challenge (Zimmerman \& Arunkumar, 1994). The protective factor 
RCS VALIDATION 8

model explains how the protective factor acts as the moderator while examining the interaction between risk and protective factors and the outcome. The protective factor model is referred to as the immunity-versus-vulnerability model by Garmezy et al. (1984). For example, peer drug use (risk factor) may have a direct effect on the adolescent's drug abuse (outcome), but a strong community support group (moderator) may interact with the risk factor to moderate the peer use and adolescent drug use relationship (Zimmerman \& Arunkumar, 1994).

The protective factor model could be useful to show how resilience-focused youth programs act as the assets or resources which could moderate or reduce the effects of a risk on a negative outcome. For purposes of this research study, a valid RCS measure that is culturally applicable to this population can potentially be used to properly assess resilience-focused youth programs implemented with American Indian youth. Resilience focused youth programs are designed to enhance protective factors, reduce risk, and most importantly build assets and resources (Blum \& Rinehart, 1997). Several resilience focused youth programs are available to help children develop skills, cope with stress, and reduce risk behavior such as alcohol and substance abuse. However, with the protective factor model approach, the building upon current assets would be an ideal approach with this population.

Sub-factors in the RCS. Protective factors contribute to resilient outcomes and represent an integral part when evaluating resilience. There are four aspects of the RCS that account for these protective factors including: (a) attachment with adults (i.e., family and nonfamily members), (b) community involvement, (c) individual characteristics, and (d) healthy relationships with peers. The protective factors in the RCS are consistent with previous research that suggest resilience promoting factors within the individual, family and peer network, and the 
community (i.e., Olsson, Bond, Burns, Vella-Brodrick, \& Sawyer, 2003). Each is discussed more fully in the following paragraphs.

Research has shown that family members and family processes can act as protective factors. For example, a healthy attachment between parent and child has been shown to contribute to a multitude of positive outcomes. However, the lack of a healthy attachment between a parent and child does not necessarily mean a harmful outcome will exist. Without the presence of a family member, a healthy relationship with an adult such as a coach, teacher, pastor, or community leader can be a significant factor in one's resilient outcome (Henley, 2010). A sample item from the RCS seeking to measure the positive relationship with a caring adult is "When I go through hard times in my life, I can ask my family for help."

Another protective factor the RCS aims to evaluate is the importance of community involvement. A person's involvement in community organizations can contribute to the development of resilience encouraging sense of worth. Community involvement can be bidirectional fostering both individual and community resilience (Henley, 2010). An individual's involvement in community activities can promote structure and stability in both the person and the community (Henley, 2010). A sample item from the RCS evaluating the community as a protective factor is "Involvement in my community and school activities makes me feel better."

Individual characteristics and responses such as empathy, self efficacy, problem solving and coping strategies are among many factors contributing to a person's resilient outcome. Adaptability, sense of humor, sense of purpose, staying focused and thinking clearly are all factors that occur in resilience (Henley, 2010). A few sample items from the RCS identifying the 
individual characteristics are "Staying positive about my future helps me get through difficult situations" and "I am a leader when times get rough."

The fourth protective factor addressed in the RCS is the healthy relationship with peers. Peers can provide an array of interactions supporting social skills and emotional development (Henley, 2010). The concept of a healthy peer relationship is captured in the RCS with a few items being evaluated: "I have at least one friend in my life who I can trust and rely on" and "I can ask my friends for help when I'm in trouble.” The RCS will be useful to evaluate youth programs promoting resilience factors to youth at risk for poor outcomes.

Developmental psychopathology. An area of study related to resilience is the field of developmental psychopathology. The field of developmental psychopathology also came into existence during the 1970's with work among children who were at risk for becoming schizophrenic. This work elicited multiple studies that examined risk factors and consequential developmental outcomes (Cicchetti, 2006). Developmental psychopathology bridges biological, psychological, and social contexts to give a better understanding of development through the lifespan when looking at normal or abnormal development (Cicchetti, 2006). An important part of developmental psychopathology is the "analysis of the risk and protective factors and mechanisms operating within and outside the individual and his or her environment over the course of development" (Cicchetti, 2006, p. 2).

Developmental psychopathologists also add an introspective approach to culture and look at how culture can influence the individual self as well as peers, family relationships, and the community as a whole (Cicchetti, 2006). For example, an individual's risk and protective factors can vary depending on their cultural norms, such as beliefs, values, and practices. An individual's culture will have his/her own philosophy of socializing his/her children to become 
the adults that the specific culture deems "normal." For example, within the American Indian population, the expectations of academic competence, social competence, and conduct may be different than they are in the dominant society. Therefore, assumptions should not be made about a particular cultural group, but rather one should gain insight from the people in the community themselves. Qualitative research designs are important to gain insights allowing for the specific culture's views and theories to be addressed. Cultural variations are apparent in most developmental issues and need to be further explored in the resilience process. Before the child is even born, culture determines how the child will be treated and such treatment has implications for the child's development throughout the lifespan (Serafica \& Vargas, 2006). Furthermore, Serafica and Vargas (2006) suggested that "culture also structures the risk and protective factors that promote or prevent the development of psychopathology" (p. 592). There is little research that identifies or validates cultural variations among the American Indian population in the field of resilience. Therefore, the validation process for the RCS measure will help shine a light on cultural variation in terms of defining resilience, because American Indian youth will provide their insights and guidance on this topic.

Conceptualizing risk and protective factors is critical in this study in which the RCS was validated as a measure of resilience for American Indian youth. Also, a critical analysis of previous literature on studies with American Indian youth and how risk and protective factors have previously been measured will help give a better understanding to demonstrate this is a needed area of research for this population. 


\section{American Indian Risk and Resilience}

American Indian at-risk nature. In considering the risk factors associated with American Indian adolescents, it is essential to understand the influences of historical trauma. It has become increasingly important to consider the impact of historical trauma in considerations of wellness when evaluating historically oppressed communities (Evans-Campbell, 2008). In order to look at the current problems American Indians face today such as substance abuse, it is critical to discuss how American Indians have been historically traumatized. Brave Heart (2003) defined historical trauma as the "collective and cumulative emotional wounding across generations" (p. 7). Although American Indian people have shown resilience despite such historical trauma, these events have placed a burden on individuals' mental health, the functioning of families, and American Indian social structures as a whole (Evans-Campbell, 2008).

American Indians have endured centuries of conflict and forced assimilation contributing to their at-risk nature. Sutton and Broken Nose (2005) explain that a continent once populated by diverse tribes that encompassed a multitude of societies, politics, religions, kinships, languages, and territories came to a halt after European colonization. Also, forced assimilation of young children through means of boarding schools was especially damaging to the family structure throughout generations of American Indians. Children sent to boarding schools experienced developmental setbacks without having their parents and culture as important socialization agents that foster healthy development (Tafoya \& del Veccheo, 2005). With the loss of family influence and their traditional beliefs and ceremonies that went unrecognized in the boarding schools, the children were impacted negatively throughout the years of boarding school experience. This greatly compromised their self-esteem, character formation, 
confirmation of womanhood and manhood, their understanding of social roles and culture, and family bonds. With the loss of the family unit, these youth never experienced proper parent/grandparent-child relationship models thus continuing cultural genocide and the multilevel and multigenerational trauma to themselves, their families, and communities (EvansCampbell, 2008). Even though boarding schools used to assimilate American Indian children into the dominant society are no longer in existence, the long term impacts are still evident in many ways today. The historical trauma of American Indians undoubtedly has been passed down from generation to generation and can be seen in present day family structure, family functioning, gender relations, parent-child relations, socioeconomic levels, and other aspects of the family (Tafoya \& Del Vecchio, 2005).

The stress of unresolved grief can greatly decrease healthy development and functioning (Brave Heart, 2003). The lack of a formal apology from the government coupled with the lack of state or government program funding that could improve living standards and decrease causes of mortality perpetuates the trauma to future generations. Tafoya and Del Vecchio (2005) suggested that without adequate resources and support, reservations lack infrastructure and access to behavioral and physical health services. Additionally, the grief of past tragedies and ongoing injustices make American Indians more vulnerable to stress, depression, chronic health problems, suicide, and substance abuse (Tafoya \& Del Vecchio, 2005).

According to the Indian Health Services (IHS), American Indians in the Phoenix IHS service area which includes the state of Arizona during 2004-2006, died at higher rates than other Americans from alcoholism (514\% higher), unintentional injuries (140\% higher), homicide (92\% higher), and suicide ( $82 \%$ higher). Also, according to the U.S. Department of Education, the high school dropout rates have consistently declined among Whites and Blacks, but the figures 
remained steady across the last several decades for the American Indian population. Statistics show that $14.6 \%$ dropped out in 2008 for the American Indian population compared to $4.8 \%$ for the White and 9.9\% for the black population (National Center for Education Statistics, 2010). Disturbing statistics also show that $25 \%$ of American Indians were living below the federal poverty level compared with $9 \%$ of non-Hispanic Whites (U.S. Census Bureau, 2004). The degree of substance and alcohol abuse problems among American Indian youth in comparison to the U.S. population as a whole is a growing concern. American Indians aged 12 or older had the highest substance dependence or abuse rate (14.1\%), compared to other racial groups (10.4\% for Latinos, 9.5\% for African American, 9.3\% for Whites, and 4.2\% for Asians) (SAMHSA, 2003). In spite of the losses associated with being historically traumatized such as the boarding school experiences, loss of land, forced assimilation, and economic and social challenges, American Indian people demonstrate great strength and resilience. American Indians demonstrate resilience through multiple ways such as within one's self, family, and community and these will be discussed more in detail in the next section of this chapter.

American Indian resilience defined. In order to have a better understanding of American Indian culture, it is important to see how Native people understand the term "resilience." Graham (2001) stated that a Lakota spiritual elder translated the term "resilience" to a sacred word that means "resistance" and said "we try to get through hard times, stressful times, with a good heart. The gift of adversity is the lesson we learn from overcoming it” (p. 1). Goodluck and Willeto (2009) suggest many American Indians define resilience through identifying broader themes such as culture, traditions, language, spirituality, family and survival. In this thesis, resilience is defined as the process in which an individual overcomes adversity by demonstrating competence in various areas such as socially, emotionally, and academically 
within their own cultural context. LaFromboise, Hoyt, Oliver and Whitbeck (2006) suggested that even though the term "resilience" has only been recently linked to the American Indian people, they have demonstrated resilience for centuries in spite of such grave historical traumas. It is important to remember and understand why the American Indian people are an at-risk population, but more importantly to look into their culture and see the positive attributes that enable American Indian youth to demonstrate resilience while faced with adversity. The following section will examine previous literature associated with resilience in American Indian youth.

Research on resilience in American Indian youth. Feinstein et al. (2009) suggested that research shows that half or two-thirds of youth overall who are faced with adversity demonstrate resilience and become successful adults (as cited in Bernard, 1995). Brendtro, Brokenleg and Van Bockern (1990) provide a framework for fostering resilience including a model called "The Circle of Courage" which resembles the native figure of the medicine wheel, comprised of four core values: belonging, mastery, independence, and generosity. The Circle of Courage philosophy emerged from research on how American Indian cultures reared responsible children without resorting to coercive discipline. It has been classified as an ethnically universal model (Brokenleg, 2010). The Circle of Courage has assisted the field of resilience research while demonstrating the importance of the fundamental themes of belonging, mastery, independence, and generosity (Brokenleg, 2010). Belonging is feeling as though one belongs within a group (i.e., family, community, or tribe). Mastery is a sense of achievement and independence giving one the power to make decisions. Generosity is being generous in spirit and giving one a sense of purpose. These four themes are important attributes within American Indian culture and are relevant in considering the process and measurement of resilience. 
Strand and Peacock (2003) conducted an extensive review of literature to further explain some common themes among American Indian cultures that foster resilience. The authors explained that American Indian people fostering resilience in their young people is not a new idea and resilience has been cultivated by focusing on four developmental areas: spirituality, mental well-being, emotional well-being, and physical well being (as cited in HeavyRunner \& Morris, 1997). Strand and Peacock (2003) further explained the results from a National Longitudinal Study of Adolescent Health (NLSAH), with a sample of 90,000 youth of all ethnicities nationally. The NSLAH study demonstrates how important the role of families, schools, and the individual characteristics of youth act as protective factors while teens are faced with adversity. Furthermore, the NLSAH reported that resilient youth overall who avoided risky behavior reported strong connections with their families, positive school relations such as high attendance, strong parent-teacher organization, low drop-outs and a high percentage of college bound students (as cited in Blum \& Rinehart, 1997). Strand and Peacock (2003) suggested that individual characteristics such as the adolescents' well being and spirituality contribute to fostering resilience. Strand and Peacock (2003) offer an extensive list of research on resilience factors among American Indian youth and many of which are discussed in the following literature review.

Fleming and Ledogar (2008) conducted a review of literature relevant to Indigenous people and communities. A great amount of American Indian research was included in this literature review. The authors emphasized the importance of community and culture in the field of resilience research and suggested that more research among Indigenous youth is needed to have a better understanding of why some youth show resilience in spite of adversity while others do not. Fleming and Ledogar (2008) suggested that four factors contribute to resilience from a 
cultural standpoint: spirituality, traditional activities, traditional languages, and traditional healing. The authors also recognized two important risk factors among Indigenous peoples: discrimination and historical trauma or unresolved historical grief. They also acknowledged the need for measures developed among Indigenous people to properly assess research involving enculturation, discrimination, historical trauma, and alcohol abuse.

HeavyRunner and Marshall (2003) discussed the promotion of resilience in American Indian students. The authors acknowledge the previous decades of research on resilience and go deeper with the cultural impact on resilience. The authors suggest the term "resilience" is an innate ability that everyone has but how they that person utilizes this trait determines their direction in life. The goal of this conceptual review was to explain how American Indian students in Tribal Colleges demonstrate resilience and what contributing factors exist. HeavyRunner and Marshall (2003) explained how spirituality among American Indian people has been one of the main reasons for survival through generations of adversity. The authors defined spirituality as growth, awareness, prayer, relationships, and the sacredness of the inner spirit. HeavyRunner and Marshall (2003) also discussed the Family Educational Model (FEM) developed by four Montana tribal colleges as a strength-based resilience approach that focuses on students' strengths that assist American Indian students from dropping out of college. With personal stories displaying true resilience, the authors stressed the importance of focusing on young people's strengths while still recognizing the risk factors.

Feinstein et al. (2009) examined resilience factors among American Indian teenagers living on a reservation while synthesizing the Circle of Courage model with Bronfenbrenner's ecological systems theory. This qualitative and quantitative research study was a two-phase process, with the first phase involving the researchers' interviewing nine high school students to 
identify qualities associated with resilience. Their responses were coded according to Bronfenbrenner's subsystems (i.e., microsystem, mesosystem, exosystem, macrosystem, chronosystem). The second phase of data collection involved the distribution of surveys to 52 high school students. This mixed method research design allowed for a real life picture of the 9 high school students interviewed and the challenges they faced while the second phase gave quantitative statistics providing empirical evidence in regards to resilience in American Indian youth. The 10 item survey resembled the interview questions and used a likert scale. The results showed the importance of extracurricular activities such as dancing in pow-wows, music, and sports act as protective factors. The results also stated that $92 \%$ of the students surveyed believed very strongly that an education was important for their future. The results showed most students surveyed and interviewed chose a role model from their nuclear or extended family (65\%), while the remaining $35 \%$ chose coaches, teachers, famous figures, or friends as their role models. The importance of parent-teacher relationships also emerged in this study, and suggested that resilient youths' parents involvement with the school helped contribute to better outcomes. These findings suggest all of the above factors can act as protective factors while faced with adversity which in turn promote resilience in youth.

Goodluck and Willeto (2009) summarized a longer paper that is one of the very few empirical studies studying American Indian resilience. The authors suggested that looking more closely at resilience, the relational worldview (mental, physical, spiritual, contextual), and American Indian strengths (tribal identity, extended family, language, traditions, spirituality) would give a better understanding of Native resilience. The method of this study was a qualitative and quantitative research design and data were collected in focus groups at a national American Indian conference. The results from this study showed how seven themes emerged 
from the focus groups, starting with ethos and values. Ethos and values referred to the beliefs and attitudes individuals are taught within their culture. Second, religion and spirituality emerged as an important theme with one participant in the focus group stating they have "always known our Indian people are resilient...we've been resilient because of our culture and our spirituality within the Creator" (Goodluck \& Willetto, 2009, p. 5). Furthermore, language, extended family and sense of humor also emerged as themes from the focus groups,

Montgomery et al. (2000) conducted a qualitative research study among 14 American Indian college students or graduates. The narratives were recorded through interviews exploring resilience factors and were analyzed for common themes. The goal of this study was to allow for the voices of the American Indian students and graduates to give rich descriptions of their resilient characteristics through narratives in regards to higher education. Results from this study suggest the importance of spirituality, but the authors use the terminology of "traditional selftalk." Through personal stories from the participants, "traditional self-talk" was associated with an inner voice that helped guide and strengthen the individual when times were tough. Another theme that emerged from this study was the concept of bicultural identity where the individual stays true to his/her Indian culture as well as functioning in the dominant society's culture. Also, a sense of ethnic pride was demonstrated with one Indian woman stating that if she were to give advice to younger Indian children she would say "I would just tell them to remember they are Indians. And to be proud of whom they are. There is nothing wrong with being an Indian. It is one of the neatest things to be" (Montgomery et al., 2000, p. 393). Youth reported that members from the tribe such as elders were influential, from their personal stories suggesting that their wisdom and encouragement helped foster their resilience. The authors concluded that the strong 
sense of family, spirituality, tribal elder support, and staying true to their ethnic identity all were contributing factors to resilience in American Indian youth (Montgomery et al., 2000).

LaFromboise, Hoyt, Oliver and Whitbeck (2006) examined the possible predictors of resilience and how family (i.e., structure and parental support), community (i.e., support and resources), and individual (i.e., self-esteem and actively engaged in one's culture) variables influence resilience among American Indians. The sample was 212 fifth through eighth graders living on or near a reservation in the Midwest and all had to be enrolled tribal members. The participants were interviewed and completed an array of surveys measuring self-esteem, enculturation, maternal warmth, community support, perceived discrimination, adversity, and resilience (Lafromboise et al., 2006). The results showed that among the youth participants, $61.6 \%$ lived in homes characterized by moderate to high levels of family adversity, as measured by poverty and parental behavior problems. The authors also concluded that youth who reported experiencing discrimination also reported less resilience. A disturbing finding emerged with age: older youth were less likely to show resilience than younger youth. The authors concluded that enculturation was the greatest predictor of higher levels of resilience. It is important to note that the measure used to show these findings was developed with the American Indian tribes, which supports the importance of using culturally applicable measures to assess how traditional culture impacts youth. Another protective factor that emerged was parental warmth, with higher levels of parental warmth associated with more resilient outcomes. Finally, community resources and support were significantly linked to positive and prosocial outcomes (LaFromboise et al., 2006). The authors explained how community support acted as an additive effect to parental warmth and enculturation. It can be concluded from this study that in spite of adversity 
associated with American Indian youth, multiple protective factors exist that contribute to resilience such as those from within the individual and the environment.

\section{Summary}

In summary, this chapter provides the reader with the background in resilience and how it has evolved over time to a more dynamic viewpoint including the relevance of culture. The atrisk nature also provides the reader with some knowledge of issues faced by American Indians throughout history and why this population is important to study because of their at-risk nature. Also, the previous literature shown in this chapter provides an important insight into American Indian culture and what protective factors contribute to resilience in American Indian youth. Therefore, this study will further explore the protective factors while examining the RCS both qualitatively and quantitatively among American Indian youth. Again, the purpose of this study was to validate the RCS for face and content validity with members from the tribe's youth council and establish validity and reliability through administering the RCS along with the already valid PIES and CES-D 10 measure to high school students. It was hypothesized that: (1) significant positive correlations would be shown between the RCS and the PIES subscales Hope and Purpose; and (2) significant negative correlation would be shown between the RCS and the CES-D 10 measures. A valid RCS will contribute to the assessment of youth programs for this specific tribe with the possibility of extension to other tribes. 
RCS VALIDATION 22

\section{CHAPTER 3}

\section{METHODS}

\section{Overview}

This mixed methods study was conducted among American Indian youth on a reservation located in Arizona. The study took part in two phases. The first was a focus group that included members of the tribal youth council who volunteered to participate. During phase 1 of data collection, the youth council members assisted the investigator in assessing the RCS measure for face and content validity during multiple focus groups over the first week of data collection. Phase 2 of data collection took place at the tribe's high school and alternative school located on the reservation. The RCS, Psychosocial Inventory of Ego Strengths (PIES) subscales Hope and Purpose, and Center for Epidemiologic Studies Depression Scale (CES-D 10) measures were administered during school hours in classrooms, cafeteria, and the counseling services office to examine concurrent and discriminant forms of validity and reliability of the RCS. The youth council members from phase 1 assisted the researcher in phase 2 of data collection and were engaged in the entire research process.

In addition to this two week period of data collection, the investigator had spent five previous trips to this reservation and these particular experiences allow the investigator's own knowledge and perceptions to be drawn upon. The community based participatory research approach (CBPR) was utilized in this research which allowed for the investigator to start the relationship building with her first visit over two years ago. The investigator observed and participated in various ceremonies, visited with the director of the cultural center on several occasions, and met with various families including a medicine man and medicine woman with this specific tribe. The CBPR is a useful approach in tribal communities starting with building 
RCS VALIDATION 23

trust and providing the community involvement and input in all phases of the research (Allen, Markstrom, Byers, \& Novins, 2011).

\section{Participants}

All members in attendance at the weekly youth council meeting over the age of 18 were invited to participate. For purposes of this paper, pseudonyms will be used to describe the youth council participants. Two volunteers (Anne and Dan) from the youth council chose to assist the investigator over the two week period. Anne is a 19 year old female who is attending her first year at a community college on the reservation. She is also the president of the tribal youth council. Dan is an 18 year old male senior in high school and serves as the president of the high school's student council. Phase 2 of data collection occurred at the reservation high school and alternative school. There were approximately 400 students enrolled at the high school and 56 at the alternative school. Table 1 presents demographic information for the $589^{\text {th }}-12^{\text {th }}$ grade males (71\%) and females (29\%). The American Indian high school students ranged in age from 15-19 with the mean age of 18 years old with the majority $(70 \%)$ reporting that they were seniors. Also, the high school students reported four different tribes all from the Southwest with the majority $(81 \%)$ reporting their tribal affiliation as the reservation where the research was being conducted.

The exact location of this reservation in Arizona will not be disclosed to protect the tribe's anonymity. Therefore, the overall American Indian population in the state of Arizona will be described. The total population in Arizona shown in the 2010 American Community Survey was 6.4 million with 285,768 reporting as AI/AN (U.S. Census Bureau, 2010). Arizona is home to 21 federally recognized tribes with reservations and tribal communities comprising over one quarter of all Arizona land (Economic Development Research Program). Consistent with the at- 
risk nature discussed in Chapter 2, similar statistics are shown with American Indians in Arizona. Alcohol is the single most serious substance abuse problem in American Indian communities (Arizona Department of Health Services, 2005). The alcohol related mortality rate among American Indians in the state of Arizona in 2003 was 49.3 deaths per 100,000 compared to 6.8 for the Black population and 8.3 for the White population (Arizona Department of Health Services, 2005). The 2010 Census Bureau reported American Indians' median household income as $\$ 29,487$ compared to $\$ 46,789$ for total population in Arizona. American Indian families reporting receiving Food Stamp/SNAP benefits was 30\% compared to $13 \%$ for total population in the state of Arizona. The poverty rate for American Indian families with children under the age of 18 was $36 \%$ compared to $20 \%$ in total population in the state of Arizona (US Census Bureau, 2010). The median age at death was reported as 59 for American Indians in Arizona compared to 77 for all Arizonans (Arizona Department of Health Services, 2008). Unintentional injuries were ranked the highest leading cause of death among American Indians on or off reservation for males in Arizona (Arizona Department of Health Service, 2008). In 1998-2008 among the unintentional injuries as a cause of death, American Indian females were nearly twice as likely to be killed in a motor-vehicle accident (66.8\%) compared to all females in the state of Arizona (Arizona Department of Health Services, 2008). As shown in the statistics and the American Indian at-risk section in Chapter 2, the challenges still exist today among this population.

\section{Procedure}

The participants in Phase 1 took part in three separate hour long focus groups (see Table 2) evaluating the RCS measure and assisted the investigator throughout the entire data collection process over two weeks. The investigator spoke to the entire youth tribal council during their 
weekly meeting on Monday, the first day of data collection. The tribal council meeting consisted of 12 youth with only three members over the age of 18 . Twelve adults were present as advisors and guests. The investigator explained the research study to everyone present at the meeting and requested that youth over the age of 18 interested in volunteering meet with the investigator in a separate room after the meeting. During the first meeting after the youth council weekly meeting, the investigator explained the research study to the three members over the age of 18 who agreed to meet with the investigator. All three members agreed to meet with the investigator the following day at the high school's counseling service office, but only two members showed up for the meeting. The investigator explained the study in further detail and gave the participants a copy of the original RCS measure along with the focus group consent form. After both participants signed the consent forms (Appendix A), the investigator gave them a youth council background information questionnaire (Appendix B). The questionnaire asked for age, sex, tribal affiliation, and current grade in school. Also, the questionnaire consisted of two questions referring to future goals, perceived barriers to obtaining these goals, and an open-ended question allowing the volunteer to tell the investigator more about him/herself. The investigator asked both participants in the focus group to help in Phase 2 of the data collection process over the following two weeks in the high school. The investigator used the community-based participatory research (CBPR) approach in all phases of this research process that facilitated a collaborative research relationship between the investigator, the youth council, the high school and the alternative school. Therefore, the investigator made it her main priority to get the community involved as much as possible throughout the study to make sure this was a positive research experience for the tribe. In order to fully immerse oneself into the culture, the investigator spent a large amount of time in the community. The investigator spent time at the 
Tribe's Cultural Center speaking with the director and listening to stories on three separate occasions. The investigator spent time in the homes of some family members on the reservation. Also, time was spent talking with parents at the high school and faculty and staff at both the high school and the alternative school when time permitted. The investigator kept field notes throughout the interactions in the community for later analysis.

Both participants from Phase 1 assisted in Phase 2 of the research study that involved discussing the importance of the research study to the high school students in individual classrooms, obtaining parental consents (Appendix C) and youth assent forms (Appendix D), and administering the RCS, PIES, and CESD measures to the high school students. The participants in Phase 1 were involved in all parts of the data collection process, therefore, benefits such as hands on experience in the field of research emerged and the investigator acted as a mentor throughout the data collection process.

After collecting the background information from the focus group participants, the investigator and the participants discussed parent consent forms procedure, the process of discussing the study with the high school students, and the process of administering the measures to the high school students in phase 2 the following week. The investigator gave both participants a copy of the RCS to take home to familiarize themselves with the items and write any comments or suggestions before discussing the measure in the focus groups. The investigator met again the following day with the focus group participants to examine the measure by reading each question aloud and discussed each item's readability and determined if the item was culturally appropriate. The participants gave verbal and written feedback to the investigator to be sure the high school students would fully understand each of the items. The participants were given the opportunity to give the investigator any suggestions about items they 
felt were missing in the measure or items they believed should not be included. After discussing each item, the investigator took notes based on the two focus group member's feedback and then revised the measure for the next focus group meeting a few days later in the first week of data collection. The investigator met with the participants and gave the revised measure to discuss and finalize before it was administered the following week to the high school students. The participants decided the format of the measure and a few individual items needed to be discussed further and revisions needed made. The investigator met one final time to give the newly revised measure to the participants for review before administering the final version to the high school students in phase 2 of data collection. A total of four meetings were held with the focus group participants over the first week to discuss the RCS and based on the participant's input and guidance, the revised RCS measure was ready to be administered the second week.

The investigator received a map of the high school and a list of each class to make sure each high school student under the age of 18 received a parent consent form. Anne assisted the investigator in explaining the research study to individual classrooms and handed out parent consent forms. Students were also advised they would receive a WVU t-shirt or WVU bag if they returned the parent consent forms and took part in the study. The investigator received a map of the high school and a list of each class to make sure each high school student under the age of 18 received a parent consent form. The investigator set up a table at the high school's health fair in the gymnasium allowing the investigator to discuss the study with the high school students and the investigator passed out parent consent forms to all students under the age of 18 who were interested in participating. The investigator gave incentives such as WVU pencils, pens, notebooks, bracelets, and WVU Native American Studies pamphlets. Also, the parent liaison for the high school spoke at the health fair requesting that students interested in the 
research study to bring back the parent consent forms. Dan reminded the students over the intercom daily to bring back parent consent forms to the office or counseling services office.

Phase 2 of the data collection process took place at the high school and alternative school over a two week period. First, the investigator worked with the high school personnel before data collection began to discuss exact dates and times the data would be collected. It was the investigator's aim to be least disruptive to the high school; therefore, data collection procedures were determined through discussion with the staff at the high school. The investigator met with the vice-principal on the first day of the data collection process and was guided to the counseling service center where the school's counselor assisted the investigator with space, maps, and gave the investigator a tour of the high school. The investigator and the counselor determined the best approach was to attend all English classes within every grade to be sure every student had the opportunity to hear about the study and receive a parent consent form. The investigator visited each grade's English class over a three day period. The investigator and Anne from Phase 1 discussed the importance of the research study to individual high school classes. The investigator was provided space in the counseling services office over a three day period during the second week of the study to administer the measures. During those three days, the investigator and both focus group participants administered the measures to the participants who had returned their parent consent forms and signed the assent form. The investigator and Anne visited all senior English classrooms to ask for participation in the study from those who were 18 years old or older. All participants over the age of 18 signed a consent form (Appendix E) before the measures were administered. The investigator and Dan went to the office to request the schedule of those who returned parent consent forms. Dan went to individual classrooms and brought the participant who returned the parent consent forms back to the counseling services office to 
complete the measures in a quiet area with either the investigator or Dan available for questions. Anne, Dan, or the investigator would explain the study once again and gave a youth assent form to be signed before administering the measures. After completing the measures, the high school participants had the choice of a WVU t-shirt or a WVU bag for taking part in the research study. The participants were also advised to put their name and number on a separate piece of paper for a $\$ 50$ gift card drawing. The researcher stored the data daily within her own files and personally transported all data back to WVU at the end of the two weeks.

\section{Instrumentation}

Demographics. Youth Council participants in Phase 1 of data collection completed a demographic survey answering questions about age, gender, current grade in school, and tribal affiliation. The demographic survey for the participants in Phase 1 gave the opportunity for the participants to respond to two open ended questions asking about future plans, goals, and perceived barriers in obtaining these goals. The second question allowed for the participant to tell the investigator more about his/her self. During Phase 2 of data collection, demographic information was collected while administering the measure and the information included: age, sex, tribal affiliation, level or grade of school, and an open ended question asking if the respondent had recently or currently experienced a difficult or challenging circumstance in his/her life and how he/she coped with the situation. This demographic information is located at the beginning of the RCS measure.

Psychosocial Inventory of Ego Strengths (PIES). The high school students completed (PIES) subscales (Appendix F) during Phase 2 of data collection. The Hope and Purpose ego strengths subscales were chosen specifically for this research study because they are both applicable to various items on the RCS measure and expected to be positively correlated with the 
RCS measure. Markstrom and Marshall (2007) explained how "ego strengths should be related to skills that individuals draw upon to cope with life's challenges" (p. 67). The original 64 item PIES scale was developed by Markstrom and colleagues measuring the eight ego strengths (i.e., Hope, Will, Purpose, Competence, Fidelity, Love, Care, and Wisdom) (Markstrom, Sabino, Turner \& Berman, 1997). The two subscales used (Hope and Purpose) each consist of 8 items that allows the respondent to answer on a five-point likert scale ranging from 1 (does not describe me well) to 5 (describes me very well). A sample item for the Hope subscale was "No matter how bad things get, I am confident they will get better." The Purpose subscale sample item was "When I think of my future, I see a definite direction for my life." Negatively phrased items were reverse weighted. Markstrom and Marshall (2007) reported the internal consistency with Cronbach's alphas for hope (.81) and purpose (.71) were in the acceptable range. Construct validity for high school students has also been demonstrated statistically, with significant positive correlations between the PIES and other psychosocial measures (Markstrom \& Marshall, 2007).

Resilience Competencies Scale (RCS). The original RCS (Appendix G) was developed by Henley (2010). The high school students completed the revised RCS measure (Appendix H) during Phase 2 of data collection. The RCS is multifaceted and accounts for a range of protective factors such as support from caregivers, peers, community, spirituality, and individual characteristics. The revised RCS consisted of 20 statements allowing the respondent to write the number in which they consider the degree to which it describes them on the line next to each item. The RCS 20 item measure allows the participant to answer on a Likert-type scale and ranging from 4 (always true) to 1 (never true). The RCS has no previous validation testing; therefore, no evidence of reliability or validity is available. To date, there are ongoing studies in 
various countries, but nothing has yet been published. "One study is being conducted currently in Tanzania cross-validating the RCS and the Connor-Davidson Resilience Scale (CD-RISC) and another study in Burundi using the RCS as a part of an HIV education program" (R. Henley, personal communication, Sept. 27, 2011). Therefore, this study is the first validation test for the RCS. Reliability and validity of the measure will be discussed in the Results section.

Center for Epidemiologic Studies Depression Scale (CES-D 10). The high school students completed the CES-D 10 item measure (Appendix I). The CES-D was first developed by researchers at the National Institute of Mental Health to measure adult's depressive symptoms (Robert, Andrews, Lewinsohn, \& Hops, 1990). A shortened version of the CES-D measure was developed by Andresen, Malmgren, Carter, and Patrick (1994) to be a useful self-report tool to screen for depressive symptoms. The CES-D 10 item measure allows the participant to circle the number indicating how frequently in the past week they experienced a particular symptom, ranging from 0 (rarely or none of the time-less than 1 day) to 3 (most or all of the time 5-7 days). A sample item of the CESD-10 item measure is "I was bothered by things that usually don't bother me." Bradley, Bagnell, and Brannen (2010) have shown the CES-D 10 to be a valid measure among adolescents. Negatively phrased items were reverse coded.

\section{Data Analysis}

Phase 1 of data collection consisted of the Youth Council participants in focus groups which allowed the investigator to test for face and content validity. Focus groups typically consist of five to eight people with similar background and experiences brought together to give input on a specific issue that affects them (Patton, 2002). However, for this research study, only two participants were eligible and willing to participate in the study. Face validity refers to whether the RCS measured what it is supposed to and in this case resilience as the construct. 
Also, content validity refers to how well the measure contains items that are tapping into the full range of resilience or whether something is missing (Greenstein, 2001).

Cronbach's alphas are assessed in Phase 2 of data collection to establish the internal consistency of each of the RCS, CES-D 10, and PIES subscales for an American Indian sample of 58 high school students. Then, concurrent validity of the RCS was investigated through correlation analysis between the RCS and PIES subscales. Concurrent validity was used to demonstrate how the RCS measure would be correlated with an already-validated resilience measure (i.e., PIES subscales). Discriminant validity was examined by correlation analysis between the RCS and CES-D 10. 


\section{CHAPTER 4}

\section{RESULTS}

\section{Overview}

The following section will provide both qualitative and quantitative results from the study. The qualitative section, which is based on data from focus group participants, will provide more detailed demographic information than the quantitative survey could provide. The focus group's revision of the items on the RCS will be described. Also, the protective factors associated with the RCS will be discussed in the qualitative results. The quantitative data will be explained, including Cronbach's alphas for all measures, and correlations are shown to demonstrate concurrent and discriminant validity for the RCS.

\section{Qualitative Results}

Context. Before describing the qualitative findings relative to the focus group participants, it is important to discuss the challenges faced on the reservation in order to understand the context in which the participants live. The tribe's high school on the reservation where the research was conducted had over 80 arrests in one school year ranging from drug related issues, arson, and various assault crimes (vice-principal, personal communication, May 9, 2011). Over the course of data collection the investigator observed the cafeteria surrounded by tribal police in bulletproof vests during the lunch hours, sometimes with up to five or six officers present at one time. There was an alcohol-related shooting at a home which resulted in a homicide over the weekend in between the two weeks of data collection. The stories of murder, alcohol-related accidents, and gang violence were all told to the investigator by members of the community and explained as common events occurring on the reservation. The investigator heard various stories involving traumatic experiences by the students, teachers, counselors, and 
community members throughout the data collection process and especially during the time spent in the career development classroom. The teacher in the career development classroom was responsible for the scholarships available to their high school seniors. She met with various parents and community members who were honoring their deceased love ones with scholarship funds. One story was particularly impressive. A parent was meeting with the teacher to pick up the applications for the scholarship she was funding in memory of her young daughter who was killed by a drunk driver a few years ago. Her daughter was an athlete at the high school and her mother told the investigator how important the scholarship was to her family to honor their daughter's life. There were numerous scholarships available in memory of youth who were killed and this too helped show the trauma that exists on the reservation currently. Even though faced with such adversity, some individuals and the community as a whole demonstrated high resilience and will be discussed further below.

Community, peer, and individual resilience observations. In spite of adversity that exists, a sense of community was witnessed by the investigator throughout her several visits. The first visit to this community was in October, 2009 and the investigator was an observer and a participant in a traditional ceremony representing a young women's puberty rite ceremony. The overwhelming sense of togetherness and appreciation for their cultural traditions was a true sight of community resilience. Another previous visit allowed for the investigator to participate in a sobriety campout over four days on this reservation with approximately 300 American Indians from the Southwest. Once again, community resilience was demonstrated by cultural traditions taking place such as sweat lodges, feasts with traditional Native foods, and a pow-wow including drumming and dancing. The investigator participated in several of the ceremonies (sweat lodge 
and traditional dancing), and witnessed a celebration of people keeping their traditions alive and truly showing a resilient community.

The first day of the two week data collection process allowed for the investigator to once again witness first hand a resilient community and especially the youth. A few weeks before data collection took place, the youth council president who was coordinating his youth to potentially assist the investigator in participating in this study was tragically killed in an auto accident. The investigator assumed the youth council meeting was going to be cancelled, but learned upon arrival at the high school that the youth council was moving forward in spite of such a tragedy. The sense of community and individual resilience witnessed that night of the youth council meeting was again overwhelming. The meeting started with prayer and honoring the former president's life through caring on his ideas and aspirations. The Tribal Council sent a message stating "keep your heads high and continue to pray." The youth were in high spirits and conducting important business for their community throughout the three hour meeting discussing an upcoming elderly clean up day, upcoming national conference, and their new youth council shirts. It was a remarkable sight to see a group of 12 youth uniting as one to serve their people and represent their tribe as leaders. The peer relationships observed seemed to play a major role in their drive to continue the youth council organization with most of them as trusted friends giving each other emotional support. An adult advisor spoke at the end of the meeting stating to the youth "you guys are different, most kids out there are looking for some fun activity such as fishing or camping, and you guys are out there giving to our community."

The more detailed demographic information given by the focus group members (Ann and Dan are pseudonyms) in phase 1 of data collection was reported in the open ended questions on the demographic survey and verbally discussed with the investigator. The focus group 
participants exhibited characteristics of resilience themselves by serving in youth leadership roles in the community and in the high school. Ann reported future plans to transfer to a university with her interests in early childhood education, nursing, and criminal justice. Ann reported, "I personally think there are no barriers when you try to pursue your dreams and accomplishments. The sky is the limit and that is what I believe all youth and everyone need to know." Ann went on to say "I love to make a difference for the betterment of my people." Dan reported his future plans as becoming a certified nursing assistant in the near future and then hoping to transfer to a university to become a nurse. Dan lives with his sister and her boyfriend because of his parents' divorce and three of his younger siblings live with their father. All of the children were taken from his mother due to severe neglect and Dan explained to the investigator how he tried keeping them all together. Dan was acting as a parent, supporting his younger siblings with food and care while trying to be a normal high school student. Without the proper resources, despite Dan's efforts, the tribe stepped in and removed all of the children from the home. One of his siblings lives off the reservation in a foster home. He reported the barriers that exist to accomplishing his future goals would be lack of financial and moral support due to his circumstances, but still believes he can achieve his goals. Hence, both participants are faced with adversity living on the reservation, but continue to demonstrate resilience in spite of their challenging circumstances. Multiple protective factors are contributing factors to their successes.

Measurement revision. The following section will discuss how the focus group participants and the investigator revised the RCS during multiple focus groups to test for face and content validity. The RCS was revised (see Table 3) based on the input and guidance the investigator received from the participants in the focus groups. For example, Dan explained how 
item 1 (i.e., "I can find solutions to problems") made him think of math problems in school. Therefore, the new version of item 1 of the revised RCS reads: "I can find answers to problems in my life." The main concern of the participants during the third focus group was the format of the measure. The original RCS required the participant to put a mark above the answer that was most accurate with possible responses ranging from not true at all, sometimes true, often true, or true nearly all the time. The focus group concluded that the best format would allow the participant to write the number that matches their response on the line next to each item and would be similar to the PIES subscales format. Therefore, the RCS format was changed, but still allowed the participant to rate each item on a four point scale from 1 (never true) to 4 (always true). Also, the focus group participants originally wanted item 8 to read "When I experience hard times, my religious beliefs keep me going," but after further discussion with the investigator, the term "spirituality" was added back into the final version (see Table 3 ). The participants believed it was important to have both religious and spirituality in the item because they believed some participants may relate to one or the other and stated "we have traditionalists who may relate to the term spirituality and we have religious people who may relate to the term religious." The focus group met again to give final approval before administering the measures to the high school students during the second week of data collection. No further changes to the RCS were made at this meeting.

\section{Quantitative Results}

Reliability. Before assessing the primary quantitative findings relative to the RCS, the RCS along with the other measures (PIES subscales Hope and Purpose, and CES-D 10) were examined for internal consistency. The closer to 1.0 reported for Cronbach's alpha, the greater the internal consistency of the items in the scale. According to George and Mallory (2003), the 
general rule of thumb for Cronbach alphas are: “_>.9-Excellent, _>.8-Good,_>.7Acceptable,_>.6-Questionable,_>.5-Poor, and <.5-Unnacceptable” (p.231). However, Field (2005) explains that when dealing with psychological constructs, values below .7 can be an acceptable level because of the diversity of the constructs being measured. All Cronbach's alphas for each measure are shown in Table 4. Reliability data for the PIES subscale Hope is presented in Table 4 consisting of 8 items (Cronbach's $\alpha=.67$ ) and item-total statistics are presented in Table 5. The PIES 8 item Purpose subscale is presented in Table 6 (Cronbach's $\alpha=$ .55). Table 7 shows item-total statistics for both PIES subscales combined which includes all 16 items (Cronbach's $\alpha=.77$ ). Combining both Hope and Purpose subscales increased the internal consistency/reliability which shows that more items in the measure will increase the Cronbach's alphas as suggested by Fields (2005). Hope and Purpose were significantly correlated as shown in Table $8(r=.64, p<.01)$, therefore, confirming it was reasonable to combine these two subscales from the same measure. Table 9 presents the item-total statistics for the CES-D 10 measure with 10 items (Cronbach's $\alpha=.79$ ) before eliminating item 4 "I felt that everything I did was an effort" which had a negative item-total correlation. After elimination of item 4, the internal consistency was improved (Cronbach's $\alpha=.83$ ) and the item-total statistics for CES-D 9 items are shown in Table 10. The RCS item-total statistics are shown in Table 11 (Cronbach's $\alpha=.84$ ). All 20 items contributed to high Cronbach's alpha with little evidence suggesting that removing any item would greatly improve the scale's internal consistency.

Concurrent validity. To establish concurrent validity, Pearson correlations were calculated between the RCS and the Hope and Purpose subscales of the PIES, both individually and with hope and purpose combined. Concurrent validity is established by significant correlations between the RCS and the PIES subscales because both are indicative of qualities of 
resilience. The RCS and Hope subscale were significantly positively correlated, $r=.58, p<.01$. Therefore, indicating that if a participant scored high on the RCS, they were likely to score high on the Hope subscale and vice versa. There was a significant positive correlation between the RCS and Purpose subscale, $r=.39, p<.01$. Again, if a participant were to score high on the RCS, they were likely to score high on the Purpose subscale and the converse. Also, the combination of Hope and Purpose subscales was significantly positively correlated with the RCS, $r=.53, p<.01$.

Discriminant validity. To determine discriminant validity, Pearson correlations were calculated between the RCS and CES-D 10 with a significant negative relation, $r=-.39, p<.01$. The significant findings between the RCS and CES-D 10 indicates that if someone scored high on the RCS, they were likely to score low on the CES-D 10 and vice versa. The significant findings between the RCS and the CES-D 10 establish discriminant validity. 


\section{CHAPTER 5}

\section{DISCUSSION}

\section{Overview}

The overarching goal of this study was to determine the reliability and validity of the RCS measure among American Indian adolescents. As previously stated, researchers (e.g., LaFromboise et al., 2006) have shown the importance of measurement development and validation among American Indians to properly assess characteristics of youth of this population. Therefore, this research study allowed for feedback and guidance from two youth leaders from the tribe to assist the investigator in modifying and validating the RCS in the first phase of data collection. A validated RCS would provide the tribe with a culturally applicable tool that could be used to evaluate the tribe's youth programs. The face and content validity was tested in the first phase of data collection with multiple focus groups with the two youth leaders which resulted in a revised RCS measure which was then subsequently administered to 58 American Indian high school students in the second phase of data collection. Acceptable Cronbach's alphas were shown for the RCS and concurrent and discriminant validity were shown through significant correlations between the RCS, Hope and Purpose subscales, and the CES-D measures. This final chapter will review all of the research findings for both qualitative and quantitative phases. Finally, this chapter will discuss the shortcomings of this research study and give future recommendations with both research and practice implications.

\section{Qualitative Analysis}

The qualitative information requested in the demographic survey for the two focus group participants was useful to show how the participants were good candidates to assist the investigator in revising the RCS measure. Also, the time spent between the investigator and the 
participants throughout the research study over a two week period allowed for the investigator to see how the community regards these two individuals as their future tribal leaders. The participants exhibited characteristics of resilience themselves, serving in youth leadership roles in the community and in the high school. The protective factors associated with resilience involve both individual and environmental characteristics (Garmezy, 1983; Henley, 2010). According to the investigator's observations, both participants in the focus group exhibited individual characteristics that promote resilience such as positive self-concept and effective communication style with the ability to problem solve. For example, Ann spoke at the youth council meeting demonstrating some of these individual characteristics especially when giving her speech for the upcoming election of the officers. When Ann was asked by the investigator how she prepared for the speech in hopes to be elected the new president after the current president of the youth council had recently been killed in an alcohol related automobile accident, she stated that "she spoke from her heart." This concept of "speaking from the heart" has been observed by the investigator many times in the American Indian community especially with the elders sometimes referring to this as spiritual guidance. Dan also spoke with confidence and presented ideas and guidance to the other youth council members. Dan was also highly regarded by the teachers and staff at the high school and always demonstrated his leadership skills throughout the time spent with him.

The presence of at least one caring adult in a person's life is characterized as a protective factor (Henley, 2010; Strand \& Peacock, 2003), and examples of this were shown for both participants. Ann's mother was present at the youth council meeting and she was an active participant serving as a mentor for the youth council. The investigator took Anne and her mother to lunch before leaving to return home after the two week data collection process and heard 
multiple stories showing the investigator how their relationship contributes to Ann's resilience. Ann's mother was planning to attend an upcoming conference in Minnesota to accompany Ann and the other youth council members to serve as a mentor and support person. Ann's mother was highly involved and gave Anne the emotional support and parental warmth that is shown to be critical in resilient outcomes (LaFromboise et al., 2006). The role of schools is important when evaluating protective factors while faced with adversity (Strand \& Peacock, 2003). The other focus group participant, Dan, showed how the school acted as a protective factor given his extremely stressful family experiences. He spent a great deal of time at school and involved in extracurricular activities that are also known to contribute to resilient outcomes (Feinstein et al., 2009). According to Garmezy's (1984) protective factor model, both school involvement and family support as shown in both participants (Ann and Dan), contributed to their resilient outcomes in spite of the risk factors. Given the at-risk nature of this population that has been shown throughout this paper, Ann and Dan demonstrated true resilience. Hence, these individuals were well-positioned to evaluate the RCS for applications among other youth in their community and establish faced and content validity.

Often at risk communities are lacking the presence of resilience and competence which in turn can lead to pathological outcomes (Sonn \& Fisher, 1998). However, this community showed survival while demonstrating and promoting resilience through carrying on cultural traditions, preserving their Native language, and a strong sense of cultural identity. Community resilience can contribute to individual resilience and vice versa providing opportunity for enhancing the well-being of American Indian youth. The opportunity for an individual contributing to their community which could potentially allow for the individual to receiving stability and a sense of belonging from the community can assist in reducing vulnerability. 
Therefore, opportunities to promote resilience (i.e., individual, family, community, and culture) are crucial in strengthening Native communities. Hence, the RCS will be useful in evaluating programs that assist in enhancing resilient outcomes.

\section{Quantitative Reliability}

The internal consistency reliability of the PIES Hope and Purpose subscales separate and combined were acceptable (above .55 individually and above .77 combined) and comparable to previous reports (see Markstrom et al., 1997). Higher Cronbach's alphas for the combined subscales may be attributed to more items in the Hope and Purpose subscales combined (16 items) indicating that the scales had acceptable internal consistency. The internal consistency reliability of the CES-D was good (above .83) and comparable to previous samples of adolescent samples (Bradley et al., 2010). The internal consistency reliability of the RCS was good (above .83), but as this study is the first validation of the RCS measure, it is unknown if this will be consistent with the internal consistency of the measure in studies currently being conducted.

\section{Quantitative Validity}

Concurrent validity was shown in Table 8 , showing significant correlations between the RCS and PIES subscales (i.e., Hope and Purpose). Markstrom et al. (2007) have shown both PIES subscales as valid measures. Therefore, we can concur that there is evidence that the RCS is a valid measure of resilience.

Discriminant validity is also shown in Table 8 by a significant negative correlation between RCS and the CES-D measure. Therefore, because the CES-D 10 is measuring depression, a participant should score in the opposite direction of the RCS. The CES-D 10 has been shown to be a valid measure among adolescents (Bradley et al., 2010). Hence, the RCS can be a valid tool as both concurrent and discriminant validity has been shown. 
RCS VALIDATION 44

\section{Recommendations for the RCS}

Culture is an important factor in the American Indian population and seen throughout the investigator's experiences from the traditional beliefs and ceremonies carrying on from generation to generation to preserving their native language. Research with American Indians have shown the relevance of culture and its impact in resilience throughout history (Goodluck \& Willeto, 2009; Tafoya \& del Vecchea, 2005; LaFromboise et al., 2006; Feinstein et al., 2006; Strand \& Peacock, 2003; Fleming \& Ledogar, 2008). Therefore, the investigator recommends for the RCS to include items reflecting cultural applicability for this population. Some suggestions for terminology for cultural items could include: (1) participation in traditional ceremonies such as coming of age ceremonies, (2) speaking the traditional language, (3) the use of traditional native plants for spiritual practices, and (4) cultural identity. The addition of culture as a sub-factor included in the RCS will allow for a more rounded approach to evaluate programs with American Indians. This addition could potentially assist in providing more evidence of the relevance of culture and its positive effects for tribal youth.

\section{Limitations}

There are a few limitations that need to be considered in this research study. First, the sample sizes of phase 1 and 2 were smaller than anticipated. As cited earlier by Patton (2002), a typical size of a focus group consists of five to eight people. Also, a larger sample in phase 2 would have allowed for factor analysis to be conducted and the possibility of factors or subscales to be identified within the RCS. Secondly, another resilience measure validated among American Indians would have been beneficial in this study. Despite its limitations, this study adds to the field in various ways and further documenting protective factors among American Indian adolescents while contributing a validated measure. 


\section{Future Contributions}

Most importantly, the tribe will have a culturally applicable tool that can empirically measure the effectiveness of youth programs on the reservation in promoting resilience. The RCS measure could make a further contribution through this revised measure that is shown to be applicable for American Indian adolescents in at least one geographical area of the country, but could be generalized to other American Indians elsewhere. Therefore, other tribes and research in the field of resilience could benefit and find this culturally applicable measure a valuable asset.

\section{Summary}

This study represents a first attempt to validate the RCS and more specifically among American Indian youth. The quantitative and qualitative approach allowed for a more fully refined research study and validation process. Allowing for the input and guidance from members of the tribe was critical in the first phase of data collection testing for face and content validity before administering the measure to the adolescent high school students in the second phase. The significant correlations found between the RCS and the PIES subscales for concurrent validity and between the RCS and CES-D 10 for discriminant validity supported the hypothesis that the RCS was a culturally applicable measure for the American Indian adolescents. 


\section{References}

Allen, J. A., Mohatt, G. V., Markstrom, C. A., Byers, L., \& Novins, D. K. (2011). “Oh no, we are just getting to Know You": The relationship in research with children and youth in Indigenous communities. Child Development Perspectives. doi: 10.1111/j.17508606.2011.00199.

Arrington, E. G. \& Wilson, M. N. (2000). A re-examination of risk and resilience during adolescence: Incorporating culture and diversity. Journal of Child and Family Studies, 9, 221-230.

Arizona Department of Health Services. (2008). Health status profile of American Indians in Arizona.Health Status and Vital Statistics Section Bureau of Public Health Statistics. Phoenix, AZ. Retrieved from www.azdhs.gov/plan.

Bernard, B. (1995). Fostering resilience in children. Urbana, IL: ERIC Clearinghouse on Elementary and Early Childhood Education. (ERIC Document Reproduction Service No. ED 386327.)

Blum, R. W., \& Rinehart, P. M. (1997). Reducing the risk: Connections that make a difference in the lives of youth. Bethesda, MD: Add Health. (ERIC Document Reproduction Service No. ED 412 459.)

Brendtro, L., Brokenleg, M., \& Van Bockern, S. (1990). Reclaiming youth at risk. Blooomington, IN: National Educational Service.

Brave Heart, M. Y. H. (2003). The historical trauma response among Natives and its relationship with substance abuse: A Lakota illustration. Journal of Psychoactive Drugs, $35,7-13$.

Brokenleg, M. (2010). The resilience revolution: Our original collaboration. Reclaiming 
Children and Youth, 18, 8-11.

Cicchetti, D. (2006). Development and psychopathology. In D. Cicchetti \& D. J. Cogen (Eds.), Developmental psychopathology: Theory and methods (Vol. 1, pp. 1-23). Hoboken, New Jersey: Wiley.

Evans-Campbell, T. (2008). Historical trauma in American Indian/Native Alaska communities: A multilevel framework for exploring impacts on individuals, families, and communities. Journal of Interpersonal Violence, 23, 316-338.

Feinstein, S., Driving-Hawk C., \& Baartman, J. (2009). Resiliency and Native American teenagers. Reclaiming Children and Youth, 18, 12-17.

Fergus, S. \& Zimmerman, M. A. (2005). Adolescent resilience: A framework for understanding healthy development in the face of risk. Annual Review Public Health, 26, 399-419.

Field, A. (2005). Discovering statistics using SPSS. ( $2^{\text {nd }}$ ed.). London: Sage.

Fleming, J., \& Ledogar, R .J. (2008). Resilience, an evolving concept: A review of literature relevant to Aboriginal research. Pimatisiwin, 6, 7-23.

Garmezy, N. (1973). Competence and adaptation in adult schizophrenic patients and children at risk. In S. R. Dean (Ed.), Schizophrenia: The first ten dream award lectures (pp. 163204). New York: MSS Information.

Garmezy, N. (1983). Stressors in childhood. In N. Garmezy \& M. Rutter (Eds.), Stress, coping, and development in childhood (pp. 43-84). New York: MacGraw Hill.

Garmezy, N. (1991). Resiliency and vulnerability to adverse developmental outcomes associated with poverty. American Behavioral Scientist, 34, 416-430.

Garmezy, N., Masten, A. S., \& Tellegen, A. (1984). The study of stress and competence in 
RCS VALIDATION 48

children: A building block for developmental psychopathology. Child Development, 55, $97-111$.

George, D., \& Mallery, P. (2003). SPSS for Windows step by step: A simple guide and reference. ( $4^{\text {th }}$ ed.). Boston: Allyn \& Bacon.

Goodluck, C., \& Willeto, A. (2009). Seeing the protective rainbow: How families survive and thrive in the American Indian and Alaska Native community. Seattle, WA: Annie E. Casey Foundation.

Graham, B. L. (2001). Resilience among American Indian youth: First Nations' youth resilience study. (Unpublished doctoral dissertation). University of Minnesota, Minnesota.

Greenstein, T. N. (2001). Methods of family research. Thousand Oaks, CA: Sage Publications.

HeavyRunner, I., \& Morris, J. B. (1997). Traditional Native culture and resilience. Research and Practice, 5, 1-6.

HeavyRunner, I., \& Marshall, K. (2003). Miracle survivors. Tribal College Journal, 14, 14-21.

Henley, R. (2010). Resilience enhancing psychosocial programmes for youth in different cultural contexts: Evaluation and research. Progress in Development Studies, 10, 295307.

LaFromboise, T. D., Hoyt, D. R., Oliver, L. \& Whitbeck, L. B. (2006). Family, community, and school influences on resilience among American Indian adolescents in the upper midwest. Journal of Community Psychology, 34, 193-209.

Luthar, S. S. (Ed.). (2003). Resilience and vulnerability: Adaptation in the context of childhood adversities. New York: Cambridge.

Luthar, S., Cicchetti, D., \& Becker, B. (2000). The construct of resilience: A critical evaluation and guidelines for future work. Child Development, 71, 543-562. 
Markstrom, C. A. \& Marshall, S. K. (2007). The psychosocial inventory of ego strengths: Examination of theory and psychometric properties. Journal of Adolescence, 30, 63-79.

Markstrom, C. A., Sabino, V. M., Turner, B., \& Berman, B. C. (1997). The Psychosocial Inventory of Ego Strengths: Development and validation of a new Eriksonian measure. Journal of Adolescence, 26, 705-732.

Masten, A. S. (2001). Ordinary magic: Resilience processes in development. American Psychologist, 56, 227-238.

Montgomery, D., Miville, M. L., Winterowd, C., Jeffries, B., \& Baysden, M. F. (2000). American Indian college students: An exploration into resiliency factors revealed through personal stories. Cultural Diversity and Ethnic Minority Psychology, 6, 387-398.

National Center for Education Statistics. (2010) U.S. Department of Education. (n.d.). Trends in High School Dropout and Completion Rates in the United States: 1972-2008. Washington, D.C. Retrieved from http://nces.ed.gov/pubs2011/2011012.pdf.

Olsson, C. A., Bond, L., Burns, J. M., Vella-Brodrick, D. A., \& Sawyer, S. M. (2003). Adolescent resilience: A concept analysis. Journal of Adolescence, 26, 1-11.

Salkind, N. J. (2008). Statistics for people who (think they) hate statistics. Thousand Oaks, CA: Sage.

Serafica, F. L. \& Vargas, L. A. (2006). Cultural diversity in the development of child psycopathology. In D. Cicchetti \& D.J. Cohen (Eds.), Developmental psychopathology. Vol. 1: Theory and methods (pp. 588-626). Hoboken, New Jersey: Wiley.

Sonn, C. C., \& Fisher, A. T. (1998). Sense of community: Community resilient responses to oppression and change. Journal of Community Psychology, 26, 457-472.

Strand, J. A., \& Peacock, T. D. (2003). Nurturing resilience and school success in American 
RCS VALIDATION 50

Indian and Alaska Native Students. The International Child and Youth Care Network, 59, retrieved January 24, 2011, from http://www.cyc-net.org/cyc-online/cycol-1203resilience.html.

Sutton, C. T. \& Broken Nose, M. A. (2005). American Indian families: An overview. In M. McGoldrick, J. Giordano, N. Garcia-Preto (Eds.), Ethnicity \& family therapy (pp. 43-54). New York: Guilford.

Tafoya, N., \& Del Vecchio, A. (2005). Back to the future: An examination of the Native American holocaust experience. In M. McGoldrick, J. Giordano, N. Garcia-Preto (Eds.), Ethnicity \& Family Therapy (pp. 55-74). New York: The Guilford Press.

U.S. Census Bureau. (2004, August). Income, poverty, and health insurance coverage in the United States: 2005. U.S. Government Printing Office, Washington D.C.

U.S. Census Bureau. (2010). American community survey. U.S. Government Printing Office, Washington D.C.

Whitbeck, L. B. (2011). The beginnings of mental health disparities: Emergent mental disorders among indigenous adolescents. In G. Carlo et al. (Eds.), Health Disparities in Youth and Families (pp. 121-149). New York: Springer.

Zimmerman, M. A., \& Arunkumar, R. (1994). Resiliency research: Implications for schools and policy. Social Policy Report, 8, 1-18. 
RCS VALIDATION 51

\title{
APPENDIX A
}

\section{Focus Group Consent Form}

\section{W-West VirginiaUniversity. \\ Office of Research Compliance}

\section{CONSENT AND INFORMATION FORM}

\author{
Focus Group Consent Form
}

Principal Investigator: Markstrom, Carol

Department:

Tracking Number:

HUMAN RESOURCES \& EDUCATION - Technology,

Learning, and Culture (TLC)

$\mathrm{H}-23180$

Study Title:

Validating the Resilience Competencies Scale (RCS) for Applications among American Indian Youth

Co-Investigator(s):

Melanie Hockenberry

Sponsor

West Virginia University

\section{Contact Persons}

You can contact Melanie Hockenberry at 304/376-9999.

For information regarding your rights as a research subject, you may contact the Office of Research Compliance at 304/293-7073.

\section{Introduction}

In addition if you would like to discuss problems, concerns, have suggestions related to research, or would like to offer input about the research, contact the Office of Research Integrity and Compliance at 304293-7073.You, , have been asked to participate in this research study, which has been explained to you by Melanie Hockenberry, B.S. This study is being conducted by Dr. Carol Markstrom, Ph.D. and Melanie Hockenberry B.S. in the Department of Technology, Learning and Culture at West Virginia University. This research is being

\begin{tabular}{lllll}
\hline Tracking n: & H-23180 & Page 1 of 4 & & \\
Approved On: & $04 / 29 / 2011$ & & Date \\
Valid Through: & $04 / 28 / 2012$ & & & \\
Last Amended: & N/A & & &
\end{tabular}


RCS VALIDATION 52

Tracking t: $\quad H-23180$

conducted to fulfill the requirements for a master's thesis in Educational Psychology in the Department of Technology, Learning and Culture at West Virginia University, under the supervision of Dr. Carol Markstrom.

\section{Purposes of the Study}

The purpose of this study is to get your input and guidance in evaluating the Resilience Competencies Scale.

\section{Description of Procedures}

Approximately 10 participants in the 1 hour focus group will first fill out a short questionnaire asking for age, sex, and two questions asking about future career goals and why they chose to volunteer in the Youth Council. After collecting the background information, the researcher will ask the participants to discuss the term "resilience" and determine their own definition before looking at the RCS measure. Next, the participants in the focus group will not be taking the measure, but simply assisting in the validity process by reading each question and discussing with the researcher if each item is clearly understood and determining if the item is culturally-appropriate and could be answered by any high school American Indian adolescent. The participants will also have the opportunity to give the researcher any suggestions about items they feel are missing in the measure or items they believe should not be included. The researcher will invite all participants in the focus group to help in Phase 2 of the data collection process over the following two weeks in the high school. If you choose to assist with Phase 2, you will be required to take a short training that provides research ethics education and the link is http://www.citiprogram.org. The participants that volunteer in Phase 2 at the high school will assist in explaining the importance of the study to the high school students over the first week and handing out parent consent forms. During the 2nd week, the volunteers will help in administering the surveys to the students over a 2 day period that will be approximately a 2 hour period each day.

\section{Risks and Discomforts}

There are no known or expected risks from participating in this study. In the event that participating in this research leads to feelings of needing help, you can reach the local Wellness Center hotline at 1-866-495-6735.

\begin{tabular}{lllll}
\hline Tracking it: & H-23180 & Page 2 of 4 & \\
Approved On: & $04 / 29 / 2011$ & & Date \\
Valid Through: & $04 / 28 / 2012$ & & \\
Last Amended: & N/A & &
\end{tabular}




\section{Alternatives}

You do not have to participate in this study.

There are no alternatives at this time. However, you may choose not to participate in the study at any time.

\section{Benefits}

If you choose to be involved in all parts of data collection, you may benefit from the hands on experience in the field of research.

\section{Financial Considerations}

You will be rewarded with a WVU t-shirt for participating in the focus group. If you choose to assist in the data collection procedures at the high school with the researcher, you will also receive a \$20 Walmart gift card at the end of the two weeks.

\section{Confidentiality}

Any information about you that is obtained as a result of your participation in this research will be kept as confidential as legally possible.

Confidentiality cannot be guaranteed in focus groups. Other participants in the focus group will know how they answer questions. The researcher will do her very best to keep all information private and confidential but absolute confidentiality cannot be guaranteed in focus groups.

\section{Voluntary Participation}

Participation in this study is voluntary. You are free to withdraw your consent to participate in this study at any time.

\begin{tabular}{lll}
\hline Tracking \#: & H-23180 & Page 3 of 4 \\
Approved On: & $04 / 29 / 2011$ & \\
Valid Through: & $04 / 28 / 2012$ & \\
Last Amended: & N/A &
\end{tabular}

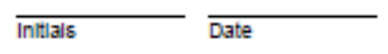


RCS VALIDATION 54

Tracking t: $\quad \mathrm{H}-23180$

Upon signing this form, you will receive a copy.

I willingly consent to participate in this research.

Signature of Subject or

Printed Name

Date

Time

Subjects Legal Representative

The participant has had the opportunity to have questions addressed. The participant willingly agrees to be in the study.

\begin{tabular}{lll}
\hline Tracking t: & H-23180 & Page 4 of 4 \\
Approved On: & $04 / 29 / 2011$ & \\
Valid Through: & $04 / 28 / 2012$ & \\
Last Amended. & N/A &
\end{tabular}

$\overline{\text { Intilals }} \overline{\text { Date }}$




\section{APPENDIX B}

\section{PHASE 1: YOUTH COUNCIL DEMOGRAPHIC INFORMATION}

What is your sex?

Female Male

How old are you?

What is your current grade?

Tribal Affiliation

What would you like to do when you graduate? Goals or plans? College? Career? Do you see any barriers in obtaining these goals?

Tell me about yourself. What would you like to tell me so I have a better idea of who you are. 
RCS VALIDATION 56

\section{APPENDIX C}

\section{Parent Consent Form}

\section{WestVirginiaUniversity. \\ Office of Research Compliance}

\section{PARENTAL OR GUARDIAN CONSENT AND INFORMATION FORM}

OMR-Parental Consent

Principal Investigator: Markstrom, Carol

Department: HUMAN RESOURCES \& EDUCATION - Technology,

Tracking Number: Learning, and Culture (TLC)

$\mathrm{H}-23180$

Study Title:

Validating the Resilience Competencies Scale (RCS) for Applications among American Indian Youth

Co-Investigator(s):

Melanie Hockenberry

\section{Sponsor}

West Virginia University

\section{Contact Persons}

You can contact Melanie Hockenberry at 304/376-9999.

For information regarding your rights as a research subject, you may contact the Office of Research Compliance at 304/293-7073.

\section{Introduction}

In addition if you would like to discuss problems, concerns, have suggestions related to research, or would like to offer input about the research, contact the Office of Research Integrity and Compliance at 304/293-7073. You, have been asked to allow your child to participate in this study, which has been explained to your child by Melanie Hockenberry, B.A. This study is being conducted by Melanie Hockenberry in the Department of Technology, Learning, and Culture at West Virginia University. This research is being conducted to fulfill the requirements for a master's thesis in Educational

\begin{tabular}{lllll}
\hline Tracking t: & $\mathrm{H}-23180$ & Page 1 of 4 & & \\
Approved On: & $04 / 29 / 2011$ & & & Date \\
Valid Through: & $04 / 28 / 2012$ & & \\
Last Amended: & N/A & & &
\end{tabular}


Tracking t: $\quad H-23180$

Psychology under the supervision of Dr. Carol Markstrom.

\section{Purposes of the Study}

The purpose is to validate a survey that will be useful for the San Carlos Wellness Center to assess and develop youth programs. WVU expects to enroll approximately 100 students from San Carlos High School.

\section{Description of Procedures}

This study involves completeing a survey and will take approximately 1015 minutes for your child to complete. Your child will be asked to fill out a questionnaire regarding helping others, determination and purpose. Your child does not have to answer all the questions. You will have the opportunity to see the questionnaire before signing this consent form if you would like to and you can reach Melanie Hockenberry at 304/376-9999.

\section{Risks and Discomforts}

There are no known or expected risks to your child from participating in this study.

\section{Alternatives}

Your child does not have to participate in this study.

\section{Benefits}

Your child may not receive any direct benefit from this study. The knowledge gained from this study may eventually benefit others.

\section{Financial Considerations}

No payments will be made for participating in the study. Your child may receive a WVU $t$-shirt or WVU bag for being in the study.

\section{Confidentiality}

Any information about you that is obtained as a result of your participation in this research will be kept as confidential as legally possible. There will be no personally identifiable information collected on any individual student

\begin{tabular}{lllll}
\hline Tracking t: & H.23180 & Page 2 of 4 & \\
Approved On: & $04 / 29 / 2011$ & & Date \\
Valid Through: & $04 / 28 / 2012$ & & \\
Last Amended: & N/A & &
\end{tabular}


RCS VALIDATION 58

Tracking \#: $\quad$ H.23180

who participates in the study in order to ensure confidentiality in the data collection process.

Voluntary Participation

Participation in this study is voluntary. You or your child may refuse to participate in this study. You or your child may withdraw from this study at any time.

$\begin{array}{lll}\text { Tracking t: } & \text { H-23180 } & \text { Page } 3 \text { of } 4 \\ \text { Approved On: } & 04 / 29 / 2011 & \\ \text { Valid Through: } & 04 / 28 / 2012 & \\ \text { Last Amended: } & \text { N/A } & \end{array}$


RCS VALIDATION 60

\section{APPENDIX D}

\section{Youth Assent Form}

\section{West VirginiaUniversity.}

\section{ASSENT FORM}

OMR-Assent

Principal Investigator: Markstrom, Carol

Department: HUMAN RESOURCES \& EDUCATION - Technology,

Tracking Number: Learning, and Culture (TLC) H-23180

Study Title:

Validating the Resilience Competencies Scale (RCS) for Applications among American Indian Youth

Co-Investigator(s):

Melanie Hockenberry

Sponsor

West Virginia University

\section{Contact Persons}

You can contact Melanie Hockenberry at 304/376-9999.

For information regarding your rights as a research subject, you may contact the Office of Research Compliance at 304/293-7073.

\section{Introduction}

In addition if you would like to discuss problems, concerns, have suggestions related to research, or would like to offer input about theresearch, contact the Office of Research Integrity and Compliance at 304/293-7073. You, have been asked to be in this research study, which has been explained to you by Melanie Hockenberry.

Purposes of the Study

You have been told that the purpose of this study is to make sure the

\begin{tabular}{lllll}
\hline Tracking \#: & H-23180 & Page 1 of 3 & & \\
Approved On: & $04 / 29 / 2011$ & & Date \\
Valid Through: & $04 / 28 / 2012$ & & \\
Last Amended. & N/A & &
\end{tabular}


RCS VALIDATION 61

Tracking \#: $\quad$ H-23180

survey is useful for your tribes Wellness Center to evaluate youth programs.

\section{Description of Procedures}

This study will be done at San Carlos High School during school hours where you will be asked to complete a survey that will take approximately 10-15 minutes to complete.

\section{Discomforts}

You should not experience any discomforts from completing the questionnaires.

\section{Benefits}

This study may not help you directly, but may provide insight and help other people.

\section{Confidentiality}

You will not identify yourself on the survey and the responses you provide will not be shared with anyone.

\section{Voluntary Participation}

You do not have to do this. No one will be mad at you if you refuse to do this or if you decide to quit. You have been allowed to ask questions about the research, and all of your questions were answered.

\begin{tabular}{lll}
\hline Tracking t: & $\mathrm{H}-23180$ & Page 2 of 3 \\
Approved On: & $04 / 29 / 2011$ & \\
Valid Through: & $04 / 28 / 2012$ & \\
Last Amended: & N/A &
\end{tabular}


RCS VALIDATION 62

Tracking \#: H.23180

I willingly agree to be in this research.

Signature of Subject

Printed Name

$\overline{\text { Date }} \overline{\text { Time }}$

The child has had the opportunity to have questions addressed. The child willingly agrees to be in the study.

Signature of Investigator or

Printed Name

Date

Co-Investigator

Tracking \#:

Approved On:

$04 / 29 / 2011$

Last Amended: N/A
Page 3 of 3

Initials

Date 
RCS VALIDATION 63

\section{APPENDIX E}

\section{8+ Consent Form}

\section{WestVirginiaUniversity. \\ Office of Research Compliance \\ CONSENT AND INFORMATION FORM}

American Indian Resilience Study

Principal Investigator: Markstrom, Carol

Department:

HUMAN RESOURCES \& EDUCATION - Technology,

Tracking Number:

Learning, and Culture (TLC)

$\mathrm{H}-23180$

Study Title:

Validating the Resilience Competencies Scale (RCS) for Applications among American Indian Youth

Co-Investigator(s):

Melanie Hockenberry

Sponsor

West Virginia University

\section{Contact Persons}

You can contact Melanie Hockenberry at 304/376-9999.

For information regarding your rights as a research subject, you may contact the Office of Research Compliance at 304/293-7073.

\section{Introduction}

In addition if you would like to discuss problems, concerns, have suggestions related to research, or would like to offer input about the research, contact the Office of Research Integrity and Compliance at 304/293-7073. You, have been asked to participate in this research study, which has been explained to you by Melanie Hockenberry, B.S. This study is being conducted by Dr. Carol Markstrom, Ph.D. and Melanie Hockenberry B.S. in the Department of Technology, Learning and Culture at West Virginia University. This research

\begin{tabular}{lllll}
\hline Tracking ": & H-23180 & Page 1 of 4 & \\
Approved On: & $04 / 29 / 2011$ & & Date \\
Valid Through: & 04/28/2012 & & \\
Last Amended: & N/A & &
\end{tabular}


is being conducted to fulfill the requirements for a master's thesis in Educational Pscyhology in the Department of Technology, Learning, and Culture at West Virginia University, under the supervision of Dr. Carol Markstrom.

\section{Purposes of the Study}

The purpose of this study is to make sure the Resilience Competencies Scale can be used with this population and properly assess the YouthPrograms on the Reservation. WVU expects to enroll approximately 100 subjects.

\section{Description of Procedures}

This study involves collection of information via questionnaires and will take approximately 15-20 minutes for you to complete. You will be asked to fill out a questionnaire regarding how you think about your own attitudes, values, and support resources. You do not have to answer all the questions. You will have the opportunity to see the questionnaire before signing this consent form.

\section{Risks and Discomforts}

There are no known or expected risks from participating in this study, except for the mild frustration associated with answering the questions.

\section{Alternatives}

You do not have to participate in this study.

There are no alternatives at this time. However you may choose not to participate in this study at any time.

\section{Benefits}

You may not receive any direct benefit from this study. The knowledge gained from this study may eventually benefit others.

\section{Financial Considerations}

The participants will be rewarded with a WVU t-shirt for participation in this

\begin{tabular}{lllll}
\hline Tracking it: & H.23180 & Page 2 of 4 & \\
Approved On: & $04 / 29 / 2011$ & & Date \\
Valid Through: & $04 / 28 / 2012$ & & \\
Last Amended: & N/A & &
\end{tabular}


RCS VALIDATION 65

Tracking \#: $\quad \mathrm{H}-23180$

research study.

Confidentiality

Any information about you that is obtained as a result of your participation in this research will be kept as confidential as legally possible. There will be no personally identifiable information collected on any individual student who participates in the study in order to ensure confidentiality in the data collection process.

\section{Voluntary Participation}

Participation in this study is voluntary. You are free to withdraw your consent to participate in this study at any time. Refusal to participate or withdrawal will involve no penalty to you. In the event new information becomes available that may affect your willingness to participate in this study, this information will be given to you so that you can make an informed decision about whether or not to continue your participation. You have been given the opportunity to ask questions about the research, and you have received answers concerning areas you did not understand.

\begin{tabular}{lll}
\hline Tracking \#: & H-23180 & Page 3 of 4 \\
Approved On: & $04 / 29 / 2011$ & \\
Valid Through: & $04 / 28 / 2012$ & \\
Last Amended: & N/A &
\end{tabular}


RCS VALIDATION 66

Tracking t: $\quad H-23180$

Upon signing this form, you will receive a copy.

I willingly consent to participate in this research.

Signature of Subject or

Printed Name

Date

Time

Subjects Legal Representative

The participant has had the opportunity to have questions addressed. The participant willingly agrees to be in the study.

\begin{tabular}{|c|c|c|}
\hline Tracking \#: & $\mathrm{H}-23180$ & Page 4 of 4 \\
\hline Approved On: & $04 / 29 / 2011$ & \\
\hline Valid Through: & $04 / 28 / 2012$ & \\
\hline Last Amended: & N/A & \\
\hline
\end{tabular}

$\overline{\text { Intilals }} \overline{\text { Date }}$




\section{APPENDIX F}

\section{Key: Psychosocial Inventory of Ego Strengths (PIES)}

Directions:

Read each item carefully and consider the degree to which it describes you.

Write the number that matches your response on the line next to each item.

\begin{tabular}{|c|c|c|c|c|}
\hline 5 & 4 & 3 & 2 & 1 \\
\hline Describes me & & & & Does not \\
very well & & & & \\
\hline
\end{tabular}

1. When I think about the future, I feel optimistic. (HOPE)

2. When things don't go my way, I remind myself of the positive things in my life.

(HOPE)

_

4. I try to pursue my aims even when I have to take risks. (PURPOSE)

_ $\mathrm{R} \_$5. I hesitate to put much energy into trying to reach my goals. (PURPOSE)

_ $\mathrm{R} \_$_ 6. I'm only setting myself up for disappointment by looking forward to things in the future. (HOPE)

7. When I think of my future, I see a definite direction for my life. (PURPOSE)

8. When something doesn't work out for me, I just look forward to doing other things.

(HOPE)

9. No matter how bad things get, I am confident they will get better. (HOPE)

R__ 10. Fear keeps me from striving for many of my goals. (PURPOSE) 
_ $\mathrm{R}$ _ 11. When I feel really down, I have a hard time believing that things are going to get better. (HOPE)

_ $R$ _ 12. I don't care about things anymore because they usually don't work out anyway. (HOPE)

13. I am able to set realistic goals for myself. (PURPOSE)

R__ 14. I hardly ever initiate activities; I usually follow the crowd. (PURPOSE)

_ $\mathrm{R}$ _ 15. When something doesn't work out the way I had hoped, it makes me feel like just quitting everything. (HOPE)

16. Even though I'm sometimes afraid of failing, if there's something I want to do I try to do it. (PURPOSE) 


\section{APPENDIX G \\ ORIGINAL RESILIENCE COMPETENCIES SCALE (RCS)}

The RCS

1. What is your age:

2. You are: male female

3. Tribal Affiliation

4. Completed to what level of school?

5. Have you recently, or are you currently experiencing especially challenging or difficult circumstances in your life?

Yes $\_$No

Instructions: Below are 20 statements - read each statement and then put a mark above the answer that is most accurate for you right now. Please use the "comments" space for any additional comments you would like to offer.

\section{I can find solutions to problems}

Not true at all Sometimes true Often true True nearly all the time

Comments:

2. Keeping hopeful about my future helps me cope in difficult situations

Not true at all Sometimes true Often true True nearly all the time

Comments:

3. I deal with unexpected events confidently

Not true at all Sometimes true Often true True nearly all the time

Comments:

4. Challenging circumstances make me stronger

Not true at all Sometimes true Often true True nearly all the time

Comments:

5. When I experience hardship I can ask my family for help and guidance

Not true at all Sometimes true Often true True nearly all the time 
Comments:

6. When I am having trouble I know where to go to get help

Not true at all Sometimes true Often true True nearly all the time

Comments:

7. I seek new knowledge that can make my situation better

Not true at all Sometimes true Often true True nearly all the time

Comments:

8. When confronted by difficulties or challenging situations my spiritual beliefs keep me going

Not true at all Sometimes true Often true True nearly all the time

Comments:

9. I lead the way when faced with obstacles to overcome

Not true at all Sometimes true Often true True nearly all the time

Comments:

10. Involvement in neighborhood activities and organizations helps me feel better

Not true at all Sometimes true Often true True nearly all the time

11. When a difficult situation happens I know what to do

Not true at all Sometimes true Often true True nearly all the time

Comments:

12. I have at least one older non-family friend in my life who I can trust and rely on Not true at all Sometimes true Often true True nearly all the time

Comments:

13. Even during hard times I try to be helpful to others

Not true at all Sometimes true Often true True nearly all the time

Comments:

14. Skills and abilities I have gained through experience help me adapt to difficulties I face Not true at all Sometimes true Often true True nearly all the time

Comments: 
15. Keeping a sense of humor helps me stay calm in tough circumstances

Not true at all

Sometimes true

Often true

True nearly all the time

Comments:

16. I can adjust in any situation

Not true at all

Sometimes true

Often true

True nearly all the time

Comments:

17. I can ask my friends for help during hard times

Not true at all

Sometimes true

Often true

True nearly all the time

Comments:

18. Although my circumstances can be difficult I believe I am doing as well as my peers

Not true at all

Sometimes true

Often true

True nearly all the time

Comments:

19. Nothing stops me from pursuing my goals

Not true at all

Sometimes true

Often true

True nearly all the time

Comments:

20. I am determined and don't give up

Not true at all

Sometimes true

Often true True nearly all the time

Comments: 


\section{REVISED RESILIENCE COMPETENCIES SCALE (RCS)}

1. What is your age:

2. You are: male female

3. Tribal Affiliation

4. What is your current grade?

5. Think about a recent challenging or difficult event in your life. First, briefly describe what happened. Then explain how you coped or dealt with the challenging situation?

\section{Directions:}

Read each item carefully and consider the degree to which it describes you. Write the number that matches your response on the line next to each item.

\begin{tabular}{|c|c|c|c|}
\hline 4 & 3 & 2 & 1 \\
& & & \\
\hline Always true & Often & Rarely & Never true \\
& True & true & \\
\hline
\end{tabular}

1. I can find answers to problems in my life

2. Staying positive about my future helps me get through difficult situations

3. I deal with unexpected events positively

4. Challenging situations make me stronger

5. When I go through hard times in my life, I can ask my family for help 
RCS VALIDATION 73

\begin{tabular}{|c|c|c|c|}
\hline 4 & 3 & 2 & 1 \\
\hline Always true & Often & Rarely & Never true \\
& True & true & \\
\hline
\end{tabular}

6. When I am having trouble I know where to go to get help

7. I can find new information that can help me and make my situation better

8. When I experience hard times, my religious/spiritual beliefs keep me going

9. I am a leader when times get rough

10. Involvement in my community and school activities makes me feel better

11. When a bad situation happens, I know what to do

12. I have at least one friend in my life who I can trust and rely on (not a family member)

13. During tough times, I try to be helpful to others

14. Everything that I have been through in difficult times will help me now and in the future

15. Laughing and joking helps me stay calm in difficult times

16. I can keep myself together in any situation

17. I can ask my friends for help when I'm in trouble

18. While faced with tough times, I know I am doing just as well as my friends

19. Nothing stops me from going after my goals

20. Once I have my mind set, I will never give up 


\section{APPENDIX I}

\section{CENTER FOR EPIDEMIOLOGIC STUDIES DEPRESSION SCALE (CES-D 10)}

Below is a list of the ways you might have felt or behaved. Please tell me how often you have felt this way during the past week (circle one of the numbers for each question).

\section{During the Past Week...}

\begin{tabular}{|c|c|c|c|c|}
\hline & $\begin{array}{l}\text { Rarely or } \\
\text { none of the } \\
\text { time (less } \\
\text { than } 1 \text { day) }\end{array}$ & $\begin{array}{l}\text { Some or a } \\
\text { little of the } \\
\text { time (1-2 } \\
\text { days) }\end{array}$ & $\begin{array}{l}\text { Occasionally } \\
\text { or a } \\
\text { moderate } \\
\text { amount of } \\
\text { time (3-4 } \\
\text { days) }\end{array}$ & $\begin{array}{l}\text { Most or all of } \\
\text { the time (5-7 } \\
\text { days) }\end{array}$ \\
\hline $\begin{array}{l}\text { 1. I was bothered by things that } \\
\text { usually don't bother me. }\end{array}$ & 0 & 1 & 2 & 3 \\
\hline $\begin{array}{l}\text { 2. I had trouble keeping my mind } \\
\text { on what I was doing. }\end{array}$ & 0 & 1 & 2 & 3 \\
\hline 3. I felt depressed. & 0 & 1 & 2 & 3 \\
\hline $\begin{array}{l}\text { 4. I felt that everything I did was } \\
\text { an effort. }\end{array}$ & 0 & 1 & 2 & 3 \\
\hline 5. I felt hopeful about the future. & 0 & 1 & 2 & 3 \\
\hline 6. I felt fearful. & 0 & 1 & 2 & 3 \\
\hline 7. My sleep was restless. & 0 & 1 & 2 & 3 \\
\hline 8. I was happy. & 0 & 1 & 2 & 3 \\
\hline 9. I felt lonely. & 0 & 1 & 2 & 3 \\
\hline 10. I could not get "going." & 0 & 1 & 2 & 3 \\
\hline
\end{tabular}


RCS VALIDATION 75

Table 1

Demographic information for high school students in phase $2(n=58)$

\begin{tabular}{|c|c|c|c|}
\hline Variable & & Frequency & Percent \\
\hline \multicolumn{4}{|l|}{ Age } \\
\hline & 15 & 6 & 10.3 \\
\hline & 16 & 6 & 10.3 \\
\hline & 17 & 2 & 3.4 \\
\hline & 18 & 40 & 69.0 \\
\hline & 19 & 4 & 6.9 \\
\hline \multicolumn{4}{|l|}{ Sex } \\
\hline & Female & 41 & 70.7 \\
\hline & Male & 17 & 29.3 \\
\hline \multicolumn{4}{|l|}{ Tribe } \\
\hline & Tribe 1 & 47 & 81.0 \\
\hline & Tribe 2 & 4 & 6.9 \\
\hline & Tribe 3 & 2 & 3.4 \\
\hline & Tribe 4 & 1 & 1.7 \\
\hline \multicolumn{4}{|l|}{ Grade } \\
\hline & $9^{\text {th }}$ & 4 & 7.1 \\
\hline & $10^{\text {th }}$ & 8 & 14.3 \\
\hline & $11^{\text {th }}$ & 3 & 5.4 \\
\hline & $12^{\text {th }}$ & 41 & 73.2 \\
\hline
\end{tabular}


Table 2

Focus Group Timeline

\begin{tabular}{|c|c|c|}
\hline $\begin{array}{l}\text { Focus } \\
\text { Group }\end{array}$ & Activity & Day \\
\hline Recruitment & $\begin{array}{l}\text { - Spoke at Youth Council Meeting } \\
\text { - Described study and asked for volunteers to stay after to } \\
\text { discuss more in depth (18+) }\end{array}$ & Monday \\
\hline $\begin{array}{l}\text { 1st Focus } \\
\text { Group }\end{array}$ & $\begin{array}{l}\text { - Youth consent forms } \\
\text { - Background questionnaire } \\
\text { - Discussed study further in detail, asked for participation } \\
\text { - Discussed parent consent procedures and administering } \\
\text { - Handed out RCS, instructed to take home and read over } \\
\text { (write comments and/or questions to discuss) } \\
\text { - Planned to meet following day to discuss RCS and start } \\
\text { revisions }\end{array}$ & Tuesday \\
\hline $\begin{array}{l}\text { 2nd Focus } \\
\text { Group }\end{array}$ & $\begin{array}{l}\text { - } \text { Read each item out loud } \\
\text { - Discussed readability }\end{array}$ & Wednesday \\
\hline
\end{tabular}


RCS VALIDATION 77

\begin{tabular}{|c|c|c|}
\hline & $\begin{array}{l}\text { - Discussed cultural applicability } \\
\text { - Made edits based on input and revised for next meeting }\end{array}$ & \\
\hline $\begin{array}{l}3^{\text {rd }} \text { Focus } \\
\text { Group }\end{array}$ & $\begin{array}{l}\text { - Discussed revised measure } \\
\text { - Format discussed and changed } \\
\text { - Few individual items discussed further } \\
\text { - Revised again }\end{array}$ & Friday \\
\hline $\begin{array}{l}\text { Final Focus } \\
\text { Group }\end{array}$ & $\begin{array}{l}\text { - Final version shown to participants for approval before } \\
\text { administering to the high school students } \\
\text { - No revisions }\end{array}$ & Friday \\
\hline
\end{tabular}


Table 3

Original Items from Resilience Competency Scale (RCS) and Revised Items after Focus Groups with American Indian Youth

\begin{tabular}{|c|c|}
\hline Original RCS items & Final Items after Focus Group Assessment and Revision \\
\hline 1. I can find solutions to problems & 1. I can find answers to problems in my life \\
\hline $\begin{array}{l}\text { 2. Keeping hopeful about my future helps me cope in difficult } \\
\text { situations }\end{array}$ & $\begin{array}{l}\text { 2. Staying positive about my future helps me get through difficult } \\
\text { situations }\end{array}$ \\
\hline 3. I deal with unexpected events confidently & 3. I deal with unexpected events positively \\
\hline 4. Challenging circumstances make me stronger & 4. Challenging situations make me stronger \\
\hline $\begin{array}{l}\text { 5. When I experience hardship I can ask my family for help and } \\
\text { guidance }\end{array}$ & $\begin{array}{l}\text { 5. When I go through hard times in my life, I can ask my family for } \\
\text { help }\end{array}$ \\
\hline 6. When I am having trouble I know where to go to get help & 6. When I am having trouble I know where to go to get help \\
\hline 7. I seek new knowledge that can make my situation better & $\begin{array}{l}\text { 7. I can find new information that can help me and make my situation } \\
\text { better }\end{array}$ \\
\hline $\begin{array}{l}\text { 8. When confronted by difficulties or challenging situations my } \\
\text { spiritual beliefs keep me going }\end{array}$ & $\begin{array}{l}\text { 8. When I experience hard times, my religious/spiritual beliefs keep } \\
\text { me going }\end{array}$ \\
\hline 9. I lead the way when faced with obstacles to overcome & 9. I am a leader when times get rough \\
\hline
\end{tabular}




\begin{tabular}{|c|c|}
\hline $\begin{array}{l}\text { 10. Involvement in neighborhood activities and organizations helps } \\
\text { me feel better }\end{array}$ & $\begin{array}{l}\text { 10. Involvement in my community and school activities makes me feel } \\
\text { better }\end{array}$ \\
\hline 11. When a difficult situation happens I know what to do & 11. When a bad situation happens,, I know what to do \\
\hline $\begin{array}{l}\text { 12. I have at least one older non-family friend in my life who I can } \\
\text { trust and rely on }\end{array}$ & $\begin{array}{l}\text { 12. I have at least one friend in my life who I can trust and rely on (not } \\
\text { a family member) }\end{array}$ \\
\hline 13. Even during hard times I try to be helpful to others & 13. During tough times, I try to be helpful to others \\
\hline $\begin{array}{l}\text { 14. Skills and abilities I have gained through experience help me } \\
\text { adapt to difficulties }\end{array}$ & $\begin{array}{l}\text { 14. Everything that I have been through in difficult times will help me } \\
\text { now and in the future }\end{array}$ \\
\hline $\begin{array}{l}\text { 15. Keeping a sense of humor helps me stay calm in tough } \\
\text { circumstances }\end{array}$ & 15. Laughing and joking helps me stay calm in difficult times \\
\hline 16. I can adjust in any situation & 16. I can keep myself together in any situation \\
\hline 17. I can ask my friends for help during hard times & 17. I can ask my friends for help when I'm in trouble \\
\hline $\begin{array}{l}\text { 18. Although my circumstances can be difficult I believe I am doing } \\
\text { as well as my peers }\end{array}$ & $\begin{array}{l}\text { 18. While faced with tough times, I know I am doing just as well as } \\
\text { my friends }\end{array}$ \\
\hline 19. Nothing stops me from pursuing my goals & 19. Nothing stops me from going after my goals \\
\hline 20. I am determined and don't give up & 20. Once I have my mind set, I will never give up \\
\hline
\end{tabular}


RCS VALIDATION 80

Table 4

Cronbach's alphas for RCS, PIES subscales, CES-D

\begin{tabular}{lll}
\hline & Cronbach's Alpha & N of Items \\
\hline RCS & .834 & 20 \\
Hope & .671 & 8 \\
Purpose & .545 & 8 \\
Hope and Purpose Combined & .767 & 16 \\
CES-D & .785 & 10 \\
CES-D & .834 & 9 \\
\hline
\end{tabular}


Table 5

Reliability Statistics for PIES Subscale Hope 8 items

Item-Total Statistics

\begin{tabular}{|c|c|c|c|c|}
\hline & $\begin{array}{l}\text { Scale Mean if } \\
\text { Item Deleted }\end{array}$ & $\begin{array}{l}\text { Scale Variance if } \\
\text { Item Deleted }\end{array}$ & $\begin{array}{c}\text { Corrected Item-Total } \\
\text { Correlation }\end{array}$ & $\begin{array}{l}\text { Cronbach's Alpha } \\
\text { if Item Deleted }\end{array}$ \\
\hline PIES1 & 24.8276 & 28.391 & .364 & .641 \\
\hline PIES2 & 24.5172 & 30.851 & .163 & .684 \\
\hline PIES6r & 24.5690 & 28.986 & .274 & .661 \\
\hline PIES8 & 24.5690 & 29.583 & .249 & .666 \\
\hline PIES9 & 24.3103 & 25.516 & .556 & .593 \\
\hline PIES11r & 24.8448 & 26.800 & .396 & .632 \\
\hline PIES12r & 24.6552 & 24.861 & .548 & .591 \\
\hline PIES15r & 24.6724 & 26.294 & .357 & .644 \\
\hline
\end{tabular}

$\mathrm{r}=$ negatively phrased items were reverse weighted 
Table 6

Reliability Statistics for PIES Subscale Purpose

Item-Total Statistics

\begin{tabular}{lrrrr}
\hline & $\begin{array}{l}\text { Scale Mean if Item } \\
\text { Deleted }\end{array}$ & Scale Variance if & Corrected Item- & Cronbach's Alpha if \\
& 24.2931 & Item Deleted & Total Correlation & Item Deleted \\
\hline PIES3r & 23.8966 & 15.965 & .581 & .373 \\
PIES4 & 24.2586 & .1879 & .535 \\
PIES5r & 24.0517 & 19.844 & .289 & .501 \\
PIES7 & 23.8448 & 19.874 & .260 & .512 \\
PIES10r & 23.7586 & 19.976 & .223 & .526 \\
PIES13 & 23.2759 & 21.186 & .333 & .489 \\
PIES14r & 23.5517 & 22.918 & .168 & .543 \\
PIES16 & & & .043 & .577 \\
\hline
\end{tabular}

$\mathrm{r}=$ negatively phrased items were reverse weighted 
Table 7

Reliability Statistics for both PIES Subscales Hope and Purpose 16 items

Item-Total Statistics

\begin{tabular}{|c|c|c|c|c|}
\hline & $\begin{array}{c}\text { Scale Mean if Item } \\
\text { Deleted }\end{array}$ & $\begin{array}{c}\text { Scale Variance if } \\
\text { Item Deleted }\end{array}$ & $\begin{array}{l}\text { Corrected Item- } \\
\text { Total Correlation }\end{array}$ & $\begin{array}{l}\text { Cronbach's Alpha } \\
\text { if Item Deleted }\end{array}$ \\
\hline PIES3r & 52.4310 & 81.969 & .489 & .743 \\
\hline PIES15r & 51.9483 & 81.559 & .452 & .747 \\
\hline PIES14r & 51.4138 & 88.492 & .282 & .762 \\
\hline PIES11r & 52.1207 & 83.757 & .433 & .749 \\
\hline PIES12r & 51.9310 & 80.311 & .578 & .735 \\
\hline PIES10r & 51.9828 & 89.210 & .214 & .769 \\
\hline PIES6r & 51.8448 & 87.502 & .315 & .759 \\
\hline PIES5r & 52.3966 & 89.226 & .248 & .765 \\
\hline PIES16 & 51.6897 & 93.446 & .090 & .775 \\
\hline PIES13 & 51.8966 & 84.129 & .535 & .742 \\
\hline PIES9 & 51.5862 & 81.650 & .575 & .737 \\
\hline PIES8 & 51.8448 & 87.361 & .341 & .757 \\
\hline PIES7 & 52.1897 & 85.876 & .370 & .755 \\
\hline PIES4 & 52.0345 & 88.244 & .369 & .755 \\
\hline PIES1 & 52.1034 & 88.445 & .307 & .760 \\
\hline PIES2 & 51.7931 & 91.816 & .153 & .771 \\
\hline
\end{tabular}

$\mathrm{r}=$ negatively phrased items were reverse weighted 
RCS VALIDATION 84

\section{Table 8}

Correlations Between RCS and PIES subscales (Hope and Purpose), and CES-D Measures

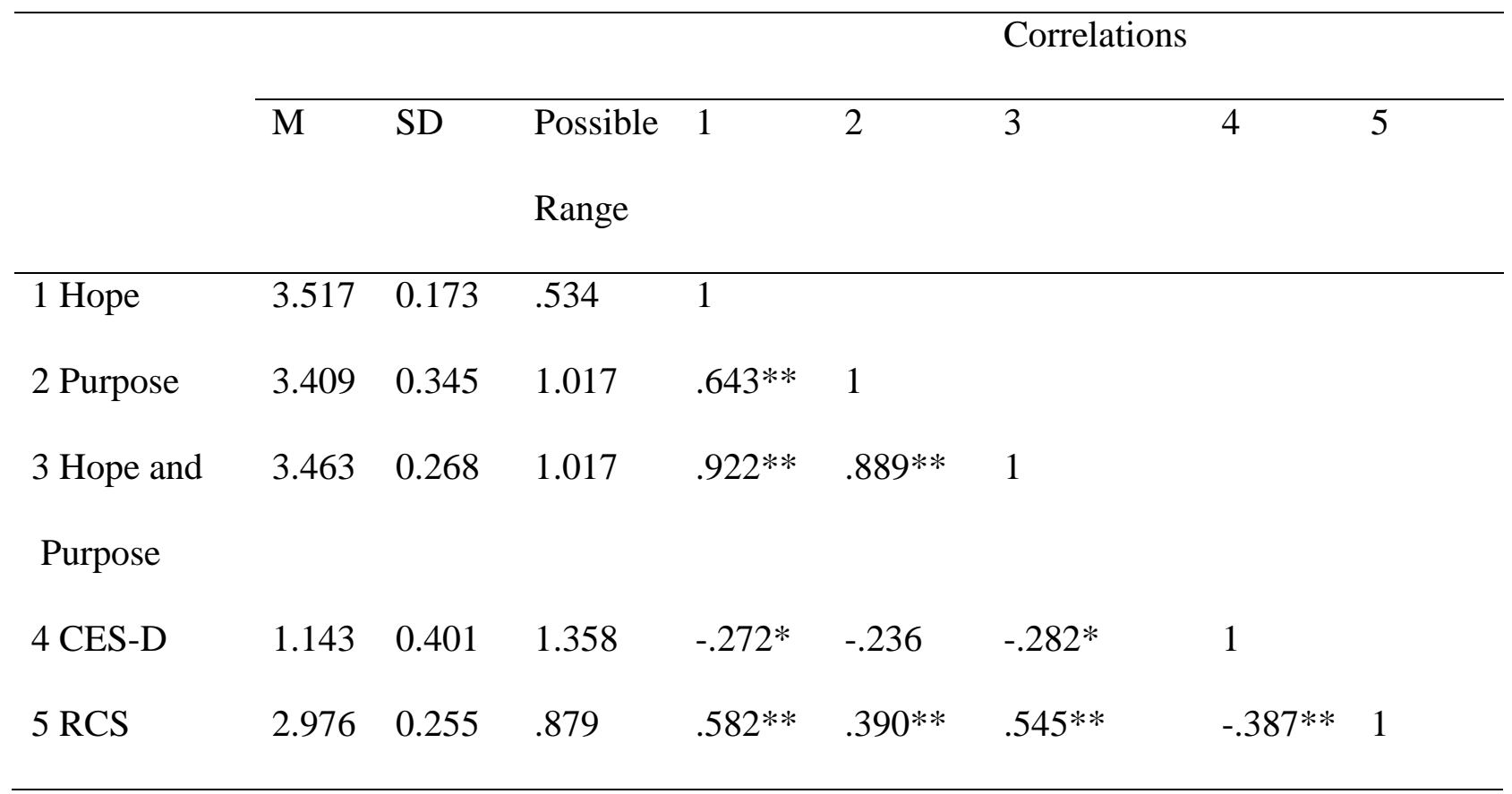

Note. ${ }^{*} p<.05, * * p<.01$ (two-tailed). 
Table 9

Reliability Statistics for CES-D 10 items

Item-Total Statistics

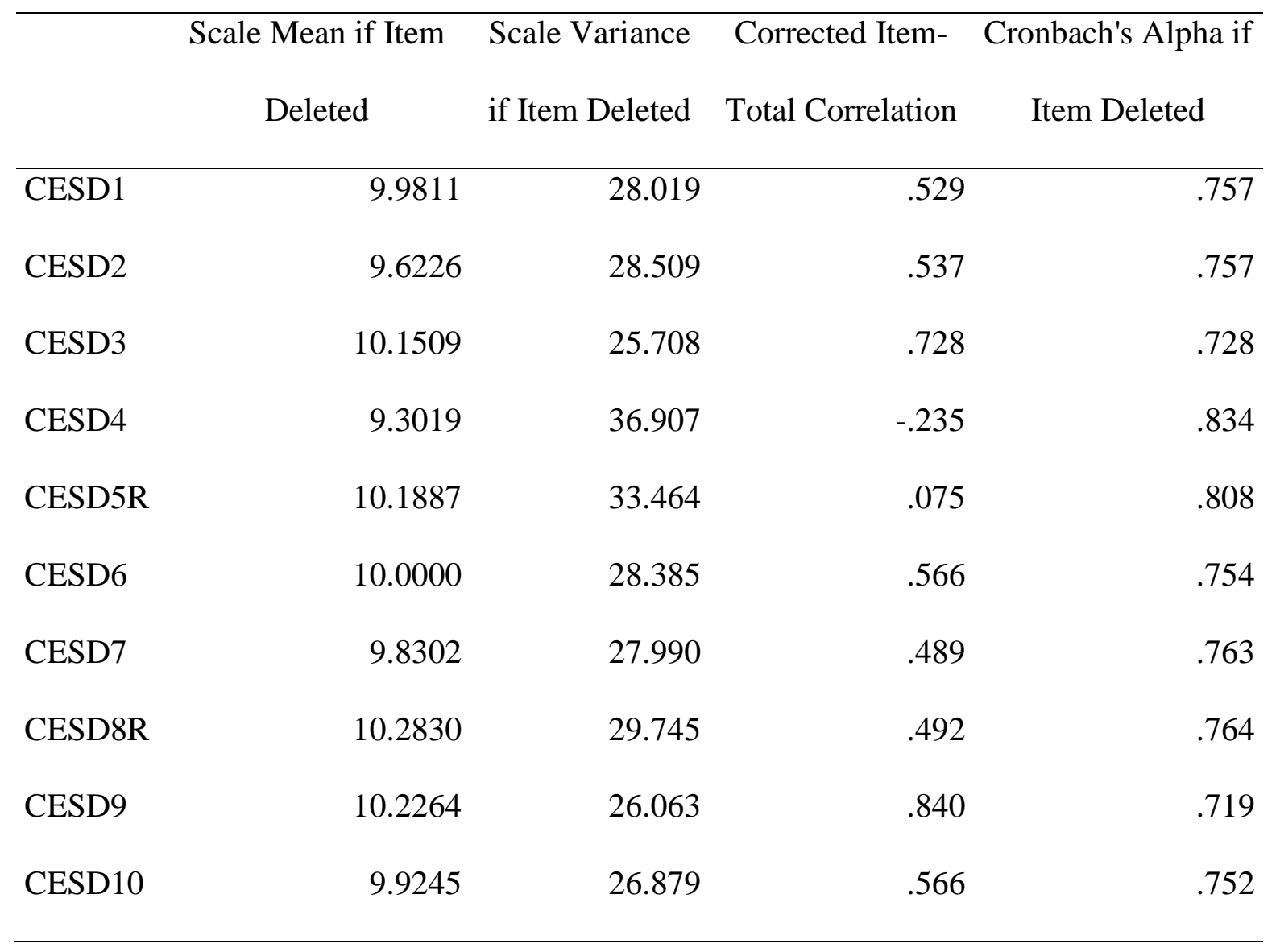

$\mathrm{r}=$ negatively phrased items were reverse weighted 
Table 10

Reliability Statistics for CES-D 9 items after deletion of item 4

\section{Item-Total Statistics}

\begin{tabular}{lrrrr}
\hline & $\begin{array}{l}\text { Scale Mean if Item } \\
\text { Deleted }\end{array}$ & Scale Variance if & Corrected Item- & Cronbach's Alpha if \\
& & Item Deleted & Total Correlation & Item Deleted \\
\hline CESD1 & 8.2264 & 30.102 & .481 & .824 \\
CESD2 & 7.8679 & 30.232 & .523 & .819 \\
CESD3 & 8.3962 & 26.975 & .751 & .791 \\
CESD5R & 8.4340 & 34.135 & .171 & .853 \\
CESD6 & 8.2453 & 30.227 & .539 & .818 \\
CESD7 & 8.0755 & 29.494 & .495 & .823 \\
CESD8R & 8.5283 & 30.792 & .556 & .817 \\
CESD9 & 8.4717 & 27.600 & .836 & .785 \\
CESD10 & 8.1698 & 28.336 & .573 & .814 \\
\hline
\end{tabular}

$\mathrm{r}=$ negatively phrased items were reverse weighted 
Table 11

Reliability Statistics for RCS 20 items

Item-Total Statistics

\begin{tabular}{|c|c|c|c|c|}
\hline & $\begin{array}{c}\text { Scale Mean if Item } \\
\text { Deleted }\end{array}$ & $\begin{array}{l}\text { Scale Variance if } \\
\text { Item Deleted }\end{array}$ & $\begin{array}{l}\text { Corrected Item- } \\
\text { Total Correlation }\end{array}$ & $\begin{array}{c}\text { Cronbach's Alpha if } \\
\text { Item Deleted }\end{array}$ \\
\hline $\mathrm{RCS} 1$ & 56.76 & 76.081 & .262 & .843 \\
\hline RCS2 & 56.24 & 73.520 & .446 & .837 \\
\hline RCS3 & 56.91 & 74.080 & .399 & .839 \\
\hline RCS4 & 56.26 & 71.528 & .538 & .833 \\
\hline RCS5 & 56.71 & 71.404 & .374 & .841 \\
\hline RCS6 & 56.64 & 69.217 & .525 & .833 \\
\hline RCS7 & 56.72 & 71.502 & .569 & .832 \\
\hline RCS8 & 56.84 & 70.204 & .426 & .838 \\
\hline RCS9 & 56.95 & 73.418 & .362 & .840 \\
\hline RCS10 & 56.50 & 70.640 & .544 & .832 \\
\hline RCS11 & 56.79 & 70.062 & .625 & .829 \\
\hline RCS12 & 56.38 & 76.626 & .108 & .855 \\
\hline $\mathrm{RCS} 13$ & 56.38 & 74.520 & .420 & .838 \\
\hline RCS14 & 56.29 & 70.527 & .621 & .829 \\
\hline RCS15 & 56.07 & 73.820 & .487 & .836 \\
\hline RCS16 & 56.48 & 76.815 & .207 & .845 \\
\hline RCS17 & 56.45 & 73.690 & .329 & .842 \\
\hline
\end{tabular}


RCS VALIDATION 88

\section{Item-Total Statistics}

\begin{tabular}{|c|c|c|c|c|}
\hline & Scale Mean if Item & Scale Variance if & Corrected Item- & Cronbach's Alpha if \\
\hline & Deleted & Item Deleted & Total Correlation & Item Deleted \\
\hline RCS18 & 56.76 & 72.678 & 472 & .836 \\
\hline RCS19 & 56.28 & 71.045 & .633 & .830 \\
\hline RCS20 & 56.41 & 73.966 & .350 & 841 \\
\hline
\end{tabular}

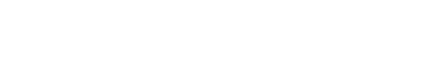

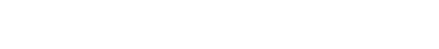

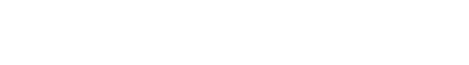

